\title{
Physical-Statistical Model for Summer Extreme Temperature Events over South Korea
}

\author{
WON-IL LIM AND KYONG-HWAN SEO \\ Department of Atmospheric Sciences, Division of Earth Environmental System, Pusan National University, Busan, South Korea
}

(Manuscript received 4 April 2018, in final form 30 December 2018)

\begin{abstract}
Extreme temperature events have a significant impact on human life and property. Since the Korean Peninsula is affected by the high variability of the East Asian summer monsoon system, it is difficult to predict extreme temperature events skillfully. Here, we construct an empirical model to investigate the interannual variation of the frequency of summer extreme temperature events over South Korea by identifying predictors (explanatory variables) from ocean boundary conditions. The selected explanatory variables are sea surface temperature anomalies (SSTAs) over the North Atlantic, the western North Pacific, and the eastern North Pacific. The cross-validated correlation skill of the statistical model constructed using a 23-yr dataset is estimated to be 0.77. A common feature that all three explanatory variables contain is the development of an anticyclonic circulation anomaly over the Korean Peninsula. The North Atlantic SSTA predictor acts as a forcing mechanism for the generation of Rossby wave trains downstream, developing an anticyclonic circulation anomaly in the lower and upper troposphere over the Korean Peninsula. The western North Pacific (WNP) warm SSTA predictor induces a cyclonic circulation anomaly over the WNP and an anticyclonic circulation anomaly over the Korean Peninsula, resembling the Pacific-Japan teleconnection mechanism that represents the northward Rossby wave propagation over the western Pacific. Through air-sea interaction, the tripolar SSTA pattern in the eastern North Pacific representing the North Pacific gyre oscillation induces two opposite precipitation anomalies in the equatorial Maritime Continent and the Philippine Sea. These diabatic anomalies excite northward-propagating Rossby waves that form a cyclonic circulation anomaly in the WNP area and an anticyclonic anomaly over the Korean Peninsula.
\end{abstract}

\section{Introduction}

Extreme temperature events for several days in the summer have seriously damaged society, human life, the economy, and ecosystems (e.g., Field et al. 2012; Hartmann et al. 2014; Perkins et al. 2015). In particular, the high mortality rate in South Korea over the past 100 years is associated with the frequent occurrence of extreme high temperatures (Kysely and Kim 2009). The Intergovernmental Panel on Climate Change (IPCC) concluded that global warming has caused an increase in the number of warm days since 1950, with the frequency of extremely high temperature events also having increased in many regions, including Europe, Asia, and Australia (Field et al. 2012; Hartmann et al. 2014).

It is widely known that the frequency of extreme high temperatures increases as global warming accelerates and as the mean temperature rises (Coumou et al. 2013; Horton et al. 2015). However, the recent extreme

Corresponding author: Dr. Kyong-Hwan Seo, khseo@pusan.ac.kr high-temperature events are not explained solely by the aforementioned thermodynamic effects of global warming (Horton et al. 2015; Kornhuber et al. 2017). Rather, they are affected by dynamic effects such as a Rossby wave teleconnection pattern and atmospheric blocking as revealed in the record-breaking high temperature cases that occurred across Europe in 2003 and over Russia in 2010 (Black et al. 2004; Lau and Kim 2012; Schubert et al. 2014). Recently, Horton et al. (2015), using self-organizing map cluster analysis, demonstrated an increasing trend in the occurrence of the atmospheric circulation pattern that induces frequent and long-persisting anticyclonic circulation anomaly events in North America, Europe, and western Asia. Both thermodynamic and dynamic factors are found to be responsible for the more frequent extreme hightemperature events in recent years.

Interannual variability of summertime climate over the Korean Peninsula is largely controlled by the East Asian summer monsoon (EASM). It is obvious that local effects influence extreme weather events, including mountain or topographic effects or land-sea contrast, 
and the related changes in atmospheric and surface radiation and sensible heat fluxes. However, extreme weather phenomena over East Asia are affected by teleconnections by remote forcing. As a tropical forcing example, oceanic variability such as El Niño-Southern Oscillation (ENSO) plays an enormous role in modulating the EASM and its subcomponents: the mei-yu, changma, and baiu rainfall patterns (Wang et al. 2000; Seo et al. 2011). Through the air-sea interaction, the eastern El Niño signal can induce an anticyclonic circulation anomaly over the Philippine Sea (Wang et al. 2000), and the related anomalous convective heating can excite the northwardor northeastward-propagating Rossby wave that forms the well-known Pacific-Japan (PJ) pattern (e.g., Nitta 1987; Wang et al. 2000; Yim et al. 2008), affecting the Korean Peninsula (Seo et al. 2011) and the North Pacific. An extremely high temperature event that occurred over Japan during 2013 and 2015 is mainly attributed to the PJ teleconnection (Imada et al. 2014; Takahashi et al. 2016). Similarly, the decaying phase of El Niño can give rise to Indian Ocean warming in spring, which produces sinking motions over the western North Pacific (WNP) area and develops the WNP subtropical high in the following season (Xie et al. 2009). In this way convective forcing over the WNP excites Rossby waves, and the precipitation and temperature in the downstream region can be changed. The cooling over the central Pacific region directly induces the WNP subtropical high as a Gill-type response (Wang et al. 2013).

Apart from the tropical effects, extratropical factors such as the North Atlantic Oscillation (NAO) and the associated sea surface temperature anomaly (SSTA) pattern in the North Atlantic also modulate the EASM and induce an anomalous geopotential height over the Korean Peninsula on interannual time scales through the eastward propagation of Rossby waves across the Eurasian continent (Ding and Wang 2005; Wu et al. 2009; Seo et al. 2012; Lee and Seo 2013; Park et al. 2015). In addition, a blocking episode in relation to Okhotsk high variability is found to significantly change the temperature in East Asia through an enhancement and persistence of the anticyclonic circulation anomaly due to the stagnation of the atmospheric circulation pattern (Nakamura and Fukamachi 2004). Therefore, understanding the dynamic processes of the atmospheric circulation pattern formed by a remote forcing is of importance for estimating or predicting the interannual variation of the frequency of extreme temperature events over the Korean Peninsula.

The EASM exhibits complex temporal and spatial variations, and so various contemporary dynamic forecast models experience difficulty in skillfully forecasting the temperature and precipitation events. As an example, Climate Forecast System version 2 (CFSv2) reforecasts and operation model outputs (Saha et al. 2014) produce considerably lower levels of prediction skill (correlation of $\sim 0.25$ ) both in summer mean and extreme temperatures over East Asia for the period from 1995 to 2017 (not shown). Accordingly, a statistical model (but based on the physical processes) can be an alternative tool for the practical seasonal prediction or diagnosis of the EASM (Wang et al. 2005; Seo et al. 2015; Jeong et al. 2017) and showed a reasonable level of performance (Wang et al. 2009, 2013; Wu et al. 2009; Fan et al. 2012). Although for the prediction of the Korean EASM (changma) precipitation (Lee and Seo 2013; Kim et al. 2017) and its onset (Park et al. 2015), empirical models are developed using SST anomalies in the Pacific and Atlantic Ocean basins as an explanatory variable, there are no studies that present a statistical model that relates to the interannually varying frequency of extreme high-temperature events. Here, we develop a physical-statistical model for this frequency using the tropical and extratropical SST anomalies. This paper is organized as follows. Section 2 describes the data and methods used in this study, while section 3 exhibits the selected independent variables and identifies the dynamical processes of the independent variables. Section 4 presents the completed empirical model and verifies the model performance. A summary is provided in section 5 .

\section{Data and methods}

The observed hourly temperature data used in this study are derived from the Korea Meteorological Administration's (KMA) 45 stations for the period from 1995 to 2017. The meteorological stations are approximately uniformly distributed across South Korea, except for the islands. To select the explanatory variables of the empirical model, we used high-resolution daily mean data from the National Oceanic and Atmospheric Administration (NOAA) optimum interpolation (OI) SST version 2 spanning from 1995 to 2017. This dataset has a horizontal resolution of $0.25^{\circ} \times 0.25^{\circ}$ (Reynolds et al. 2007), and this is interpolated to a $1^{\circ} \times 1^{\circ}$ grid system. To understand the dynamical processes of the selected explanatory variables for the diagnosis or prediction of the interannual frequency of extreme temperature events over South Korea, atmospheric variables and precipitation data are used. The atmospheric variables, including 2-m temperature, zonal and meridional winds, and geopotential height (GPH) from the National Centers for Environmental Prediction-Department of Energy (NCEP-DOE) Global Reanalysis 2 (R2) monthly mean 
dataset, have a horizontal resolution of $2.5^{\circ} \times 2.5^{\circ}$ with 17 pressure levels (except for 2-m temperature; Kanamitsu et al. 2002). The monthly mean Global Precipitation Climatology Project (GPCP) data, with a horizontal resolution of $2.5^{\circ} \times 2.5^{\circ}$, are used (Huffman et al. 1997). The training period for all the data is from 1995 to 2014 .

\section{a. Extreme temperature index}

In this study, TX90p, which is the number of days (or percentage of days relative to the 92 days) with the daily maximum temperature being greater than 90th percentile calculated based on daily climatology for the months of June-August (JJA) in the Northern Hemisphere for a given year, is used to represent extreme temperature events. This quantity is recommended by the Joint World Meteorological Organization (WMO) Commission for Climatology (CCI)-Climate and Ocean: Variability, Predictability and Change (CLIVAR)-Joint Technical Commission for Oceanography and Marine Meteorology (JCOMM) Expert Team on Climate Change Detection and Indices (ETCCDI). The yearly time series of this quantity is referred to as the TX90p index in this study. Using this index causes extreme high-temperature events be chosen for each Julian day during JJA so June has a similar sample number to that of July and August. This method is in contrast with previous studies in that we use a fixed threshold for the entire summer period or July and August only (e.g., Colombo et al. 1999; Lee and Lee 2016). Using a fixed threshold has an advantage in relation to extreme high temperature events causing damage to humans.

The EASM and western North Pacific summer monsoon are reported to exhibit significant interdecadal changes at around 1993-94 (Kwon et al. 2005). A Lepage test (Lepage 1971; Yonetani and McCabe 1994), using our TX90p index time series, also shows a statistically significant change in around 1995 (not shown) so the data period begins in 1995 in this study. A preliminary test that includes the hindcast from 1982 to 1994 using the model constructed during the training period from 1995 to 2014 showed a greatly reduced skill score (not shown), as expected from a decadal change effect.

\section{b. Statistical model and assessment}

A multiple linear regression method is used to construct a statistical model (Wilks 2006; Lee and Seo 2013; Park et al. 2015; Seo et al. 2015; Kim et al. 2017). To prevent overfitting (Wilks 2006), the number of explanatory variables is limited to three, which is consistent with an empirical estimation that considers 7-10 years of training data as one degree of freedom. Compared to the response variable (the TX90p index for JJA), the potential explanatory variables are taken from the springtime SSTAs (here the ones in April and May) over the major oceans. This 1-month lead regression scheme (with target months of JJA) utilizes the characteristics that ocean variables possess: a quasi-stationary or slow evolution property and a migratory SST signal involved in air-sea interaction. The latter feature is of special interest in that the springtime SSTA area selected as a precursor signal can be evolved through air-sea interaction, resulting in SST forcing regions occurring in different areas during the summer.

Potential predictors are those having a high temporal correlation with the TX90p index, but these variables are chosen such that the correlations between them are not statistically significant (less than 0.3 ) and the variance inflation factor (VIF) is less than two. The VIF indicates how the variability of one explanatory variable is related to that of other explanatory variables in the linear regression equation [the correlation between one explanatory variable and the predictive model constructed with $n-1$ explanatory variables is $R$, then the VIF is calculated as VIF $=1 /\left(1-R^{2}\right)$; a lower VIF suggests an independent linear relationship]. A whole training data period is 20 years from 1995 to 2014 but a leave-4-yr-out cross-validation method is used by setting 16 years as the training period and 4 years as the verification period; so a total of five training sets are formed. Use of this sliding partial training dataset for training is based on previous studies that suggested the use of $70 \%-80 \%$ of the model construction period for the training period, with $20 \%-30 \%$ being used for the verification period (e.g., Blockeel and Struyf 2002). Note that forecasting the TX90p for the years 2015-17 is performed via the last cross-validation regression set (i.e., training using 1995-2010).

Assessment of the model performance is based on a correlation coefficient, the mean square skill score (MSSS; Murphy 1988), a Gerrity skill score [Gandin-Murphy skill score (GMSS)], and a contingency table. The MSSS is defined as MSSS $=1-\mathrm{MSE}_{f} / \mathrm{MES}_{c}$, where $\mathrm{MSE}_{f}$ is the mean square error (MSE) of the empirical model result and $\mathrm{MSE}_{c}$ is the MSE of the TX90p time series. The maximum value of the MSSS is 1 . A tercile skill validation scheme is employed where the response value from the empirical model is categorized as below, near, or above normal based on \pm 0.43 standard deviations of the normalized TX90p index, and the resulting $3 \times 3$ contingency table is presented (Lee and Seo 2013; Park et al. 2015; Kim et al. 2017). The off-diagonal cell in the table indicates that the empirical model result or prediction is opposite to the observations. The GMSS, which is recommended by WMO (Gandin and Murphy 1992; Gerrity 1992; WMO 2010), is calculated from the contingency table. The range of the GMSS is 
from -1 to 1 . A GMSS value of 1 indicates a perfect prediction, while zero indicates that the scheme has no skill.

\section{c. Numerical models}

To verify changes in atmospheric circulations due to diabatic forcing associated with the explanatory variables, simplified and coupled model experiments have been conducted. We used the Geophysical Fluid Dynamics Laboratory (GFDL) atmospheric general circulation model dynamic core (Gordon and Stern 1982). This is a primitive equation model with rhomboidal 30 horizontal resolution and 20 sigma $(\sigma)$ levels from 0.975 to 0.025 . The initial conditions of threedimensional temperature, zonal and meridional winds, and surface pressure fields are integrated for 31 days.

A coupled model experiment is performed to investigate the effects of the atmosphere-ocean interaction associated with an eastern North Pacific predictor. The model used in this study is the GFDL Climate Model version 2.1 (CM2.1; Delworth et al. 2006). The model consists of atmospheric, land, sea ice, and ocean models, with each model component interacting through the Flexible Modeling System (FMS) coupling system. The atmospheric model (AM2.1) uses a Lagrangian finite-volume dynamical core (Lin 2004), with $2.5^{\circ}$ longitude $\times 2^{\circ}$ latitude and 24 vertical hybrid sigmapressure levels. The land model (LM2.1) is based on the Land Dynamics Model (LaD; Milly and Shmakin 2002), with the same horizontal grid as in the atmospheric model. The sea ice model is the Sea Ice Simulator (SIS; Winton 2000) (in this study, climatological sea ice is used). The ocean component is the Modular Ocean Model (MOM; MOM5.1 in this study; Griffies 2012). This model has a constant zonal resolution of $1^{\circ}$, with a meridional resolution of $0.33^{\circ}$ at the equator and $0.67^{\circ}$ in the tropics, increasing gradually to $1^{\circ}$ toward the poles, with 50 vertical levels.

\section{Dynamic processes of selected explanatory variables}

\section{a. Predictors of the empirical model}

To identify potential explanatory variables, we calculate the correlation between the TX90p index and global SSTAs. Figure 1 shows the regressed maps of springtime and summertime SSTAs against the TX90p index for the period from 1995 to 2014. Thick contours represent statistically significant areas satisfying the $90 \%$ confidence level through the Student's $t$ test. In Figs. 1a and 1b, the North Atlantic, the WNP, and the eastern North Pacific show statistically significant correlations. Among these three potential explanatory variable areas, the North Atlantic has a dipole pattern with a warm SST anomaly to the north $\left(\sim 40^{\circ}-60^{\circ} \mathrm{N}, 60^{\circ}-20^{\circ} \mathrm{W}\right)$ and a cold SST anomaly to the south $\left(\sim 20^{\circ}-40^{\circ} \mathrm{N}, 60^{\circ}-40^{\circ} \mathrm{W}\right)$. The WNP area $\left(\sim 0^{\circ}-20^{\circ} \mathrm{N}, 120^{\circ}-140^{\circ} \mathrm{E}\right)$ has a warm SST anomaly in April, with the center migrating from the SCS to the Philippine Sea in May. The eastern North Pacific area $\left(\sim 20^{\circ}-40^{\circ} \mathrm{N}, 160^{\circ}-120^{\circ} \mathrm{W}\right)$ exhibits a warm SST anomaly in May. The time series for these three potential explanatory variable regions are referred to as North Atlantic index (NAI), western North Pacific Index (WNPI), and eastern North Pacific index (ENPI). The detailed area and period information of the selected explanatory variables is shown in Fig. 2. The correlation coefficients between the TX90p index and each explanatory variable time series are shown in Table 1. All explanatory variables have significant correlations with the TX90p index at the 95\% level. The Arctic Ocean also has a statistically significant correlation. In particular, the SSTA over the Barents Sea is considerable. However, this Barents Sea region correlates with WNPI (with $r$ of 0.36 ), so the WNPI and Arctic Ocean time series cannot be used simultaneously as explanatory variables. Since the WNPI is more robust in its own dynamics and it is relatively close to the Korean Peninsula, the Arctic Ocean is not selected as an explanatory variable. However, the warming of the Arctic Ocean can cause a reduced baroclinicity so the jet stream can be decelerated or the Arctic oscillation (AO) becomes negative, leading to changes in the midlatitude weather and climate. The detailed effect of the Arctic Ocean SST on the mean temperature or extreme temperatures over the Korean Peninsula will be investigated in a future study.

Since the correlation coefficients among the selected explanatory variables are statistically insignificant (see Table 2) and their VIFs are less than 2 (not shown), the explanatory variables are deemed independent of each other.

\section{b. Dynamic processes of NAI}

Physical processes involved in the NAI are investigated by applying the composite difference method for the 2-m temperature and SST anomalies. For this, strong and weak cases are determined by the thresholds of 1.0 and -1.0 standard deviations of the NAI, respectively. Difference maps of the 2-m temperature in JJA and the SST anomaly from April to May and in JJA are shown in Fig. 3. A high-temperature region appears clearly over eastern Asia including central China and the Korean Peninsula (Fig. 3a). In relation to the NAI (Figs. 3b,c), the North Atlantic has a tripolar SST anomaly pattern persisting until JJA. This is characterized by two positive anomalies in the tropics $\left(\sim 10^{\circ}-20^{\circ} \mathrm{N}\right)$ and subpolar region $\left(\sim 40^{\circ}-60^{\circ} \mathrm{N}\right)$, with a negative anomaly in 
(a) Apr

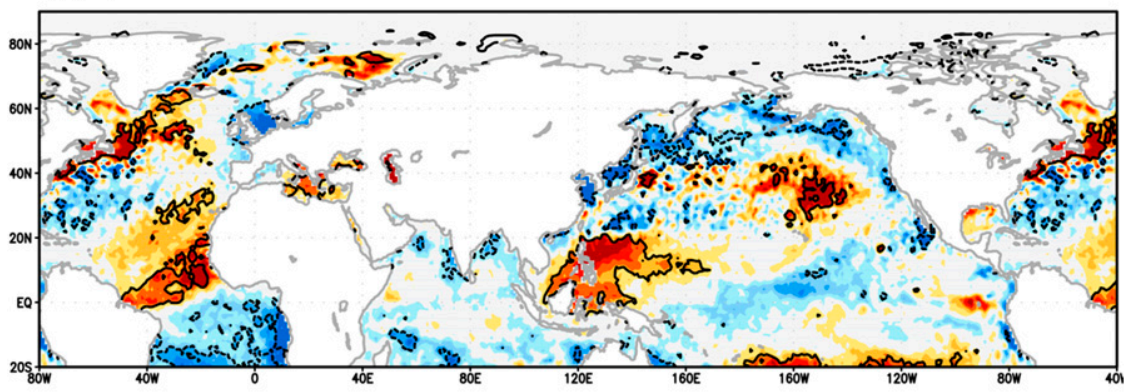

(b) May

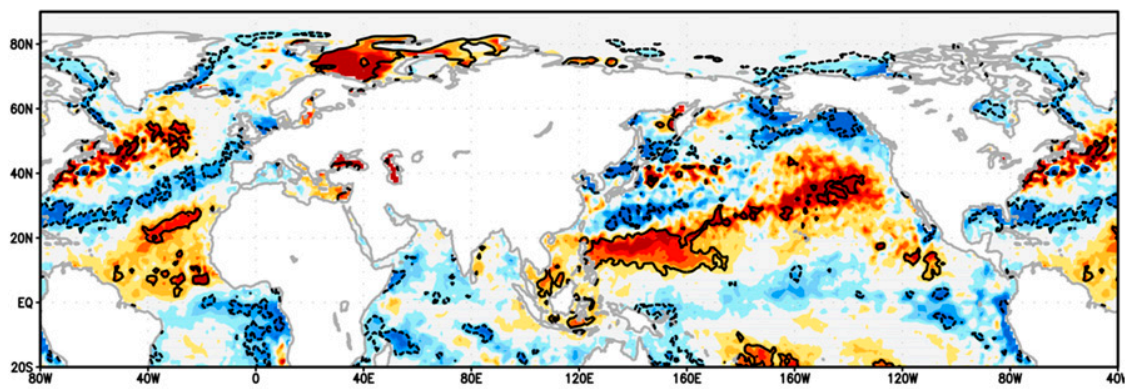

(c) JJA

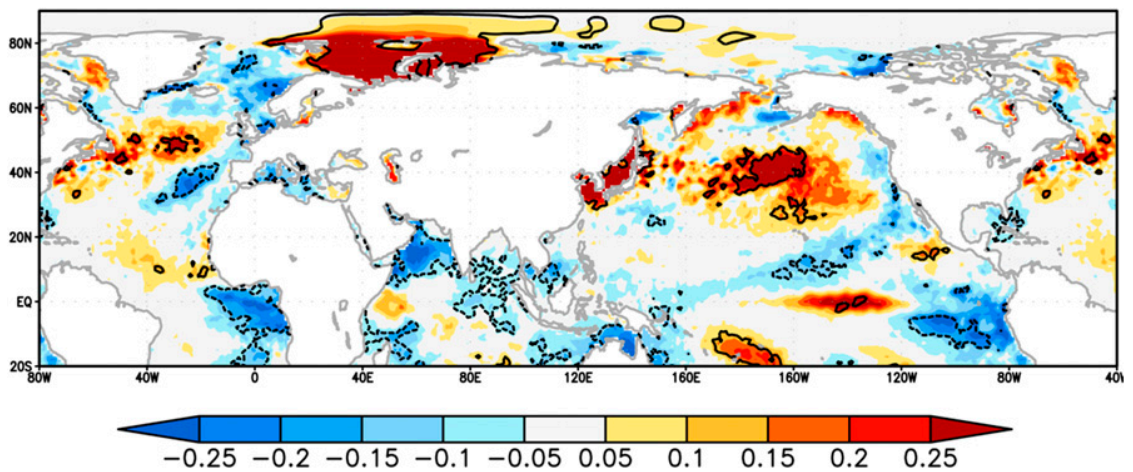

FIG. 1. Regressed SSTAs against the TX90p index (shading; K) in (a) April, (b) May, and (c) JJA for the period from 1995 to 2014. Contours represent statistically significant areas satisfying the $90 \%$ confidence level through a Student's $t$ test.

the midlatitudes $\left(\sim 20^{\circ}-40^{\circ} \mathrm{N}\right)$. This SST pattern represents the negative phase of the NAO. Similar to an apparent influence of the wintertime NAO on weather and climate in East Asia, the summertime NAO plays a role in modulating the atmospheric temperature and circulation of the downstream region through eastward-propagating Rossby waves (Wu et al. 2009). $\mathrm{Wu}$ et al. (2009) suggest that the summer tripolar SSTA pattern associated with the NAO excites a Rossby wave train across the northern Eurasian continent, thus enhancing the EASM.

Figure 4 shows the composite difference maps for the 300- and $850-\mathrm{hPa}$ GPH anomaly fields in JJA. The barotropic Rossby wave propagates northeastward over the northern Eurasian continent for $\sim 40^{\circ}-70^{\circ} \mathrm{N}$, subsequently propagating southeastward along $\sim 80^{\circ}-120^{\circ} \mathrm{E}$, which is associated with a waveguide along the north Eurasian jet ( $\sim 60^{\circ} \mathrm{N}$; Wu et al. 2009; Yamaura and Tomita 2011). After reaching the reflection latitude, the Rossby wave path is directed to the south, propagating toward the Korean Peninsula and making an anticyclonic circulation anomaly there. This barotropic structure in the higher GPH anomaly over the Korean Peninsula induces a frequent high-temperature event.

To test whether diabatic forcing in relation to the SSTAs over the North Atlantic seen in Figs. 3b or 3c can induce an anticyclonic anomaly over the Korean Peninsula, a simple forcing experiment is performed. The horizontal heating anomaly is assumed to have an elliptical squared cosine distribution (Ting and Held 1990; 


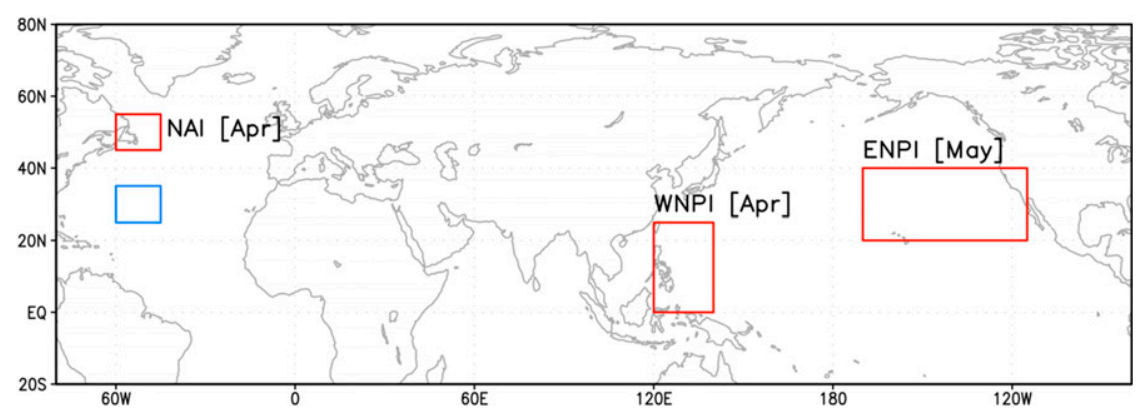

FIG. 2. Domain and period of selected explanatory variables. The red (blue) box indicates the positive (negative) SST anomaly region. The NAI is a dipole SST anomaly pattern and is calculated as positive area minus negative area.

Seo and Son 2012). In the extratropics, the vertical heating profile is in the form of $\sigma^{4}$, with a bottom-heavy profile due to shallow convection (Hall et al. 2001; Wu et al. 2009). Among the tripolar anomalies, the two higher-latitude anomalies are selected as external forcings since the lowest latitudinal anomaly (the subtropical one) does not affect much. In the GFDL dynamical core model, heating is placed over the higher latitude and cooling over the lower latitude, as seen in Fig. 5. The results in those $300-\mathrm{hPa}$ GPH anomalies show a train of the anticyclonic and cyclonic circulation anomalies appearing across the north Eurasian continent (Fig. 5a). The easternmost anticyclonic anomaly develops over the Korean Peninsula, similar to the observation (Fig. 4a). Figure $5 \mathrm{~b}$ is the ensemble-averaged $300-\mathrm{hPa} \mathrm{GPH}$ anomalies using each individual year's JJA mean state for the background state in a model. In general, the two approaches show a similar teleconnection pattern.

To sum up, the NAI index demonstrates the negative NAO-like SST pattern, which is maintained until summer (Fig. 3c), generating a Rossby wave train propagating east across the northern Eurasian continent and making an anomalous barotropic anticyclone over the Korean Peninsula. The anticyclonic circulation anomaly helps increase the incoming solar radiation to induce high surface temperatures, thus increasing the frequency of extreme temperature events (Fig. 3a).

\section{c. Dynamic process of WNPI}

Figure 6 presents the composite difference (strong weak) maps for the SST anomaly using the WNPI. Composite criteria are \pm 1.0 standard deviations, as before.

TABLE 1. Correlation coefficient between selected explanatory variables and the TX90p index for the period from 1995 to 2014.

\begin{tabular}{ccc}
\hline \hline NAI and TX90p & WNPI and TX90p & ENPI and TX90p \\
\hline 0.47 & 0.47 & 0.46 \\
\hline
\end{tabular}

In April (Fig. 6a), a positive SST anomaly develops over the WNP area, which includes the SCS and the Philippine Sea. By May, the positive SST anomaly in the SCS weakens, while the SST anomaly in the Philippine Sea remains positive (Fig. 6b). However, the latter becomes weak during JJA (Fig. 6c). The spring SSTA in the WNP decreases the local pressure in JJA (Fig. 7c), inducing low-level convergence and enhancing the precipitation (Fig. 7a). Since the relationship between precipitation and SST is moderately negative during JJA (Wang et al. 2005), positive SSTA is weaker or may disappear in the WNP (Fig. 6c). Convective heating accompanying the positive precipitation anomaly induces a cyclonic circulation as a Gill-type response (Gill 1980). In addition, the heating excites meridionally propagating Rossby waves (Ueda and Yasunari 1996; Ueda et al. 1995; Kawamura et al. 1996), producing an anticyclonic circulation anomaly (Fig. 7c) and a high temperature anomaly over the Korean Peninsula (Fig. 7b). This subtropical and extratropical circulation anomaly field is consistent with the well-known PJ teleconnection pattern (Nitta 1987).

Figure 8 represents the dynamical-core model response of the low-level GPH anomaly to initial diabatic forcing given at the location where the precipitation anomaly in the composite difference map (i.e., in the WNP; Fig. 7a) appears. In the tropics, the vertical heating profile is expressed as $(1-\sigma) \sin [\pi(1-\sigma)]$, which peaks at $\sigma=0.35$ (Lin 2009; Wu et al. 2009). The model results are similar to the observations,

TABLE 2. Correlation coefficients among selected explanatory variables for the period from 1995 to 2014.

\begin{tabular}{lccc}
\hline \hline & NAI & WNPI & ENPI \\
\hline NAI & 1 & -0.15 & -0.16 \\
WNPI & -0.15 & 1 & -0.03 \\
ENPI & -0.16 & -0.03 & 1 \\
\hline
\end{tabular}


(a) 2-m temperature (JJA)

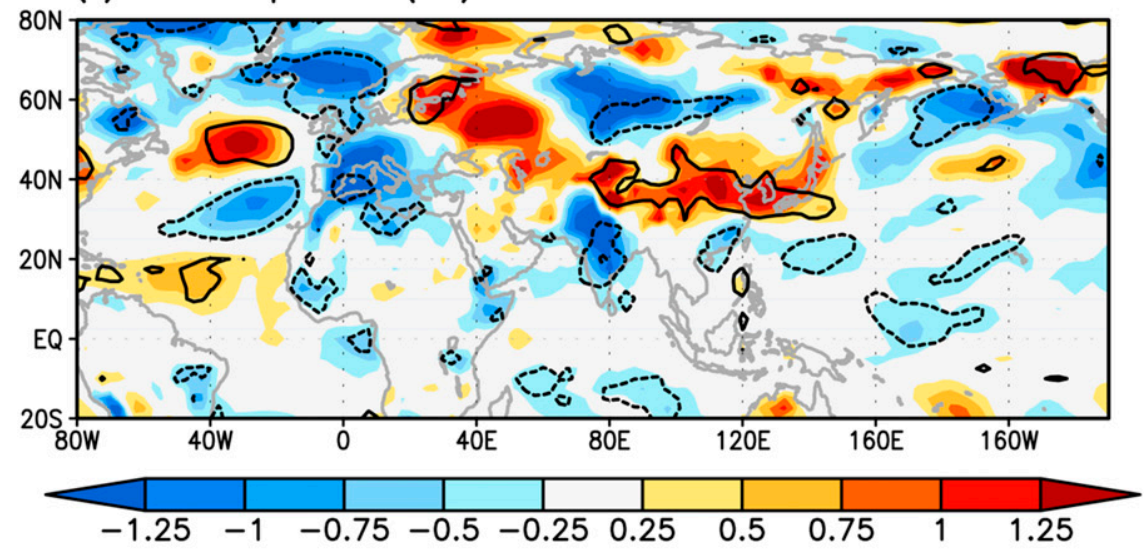

(b) SST (AM)

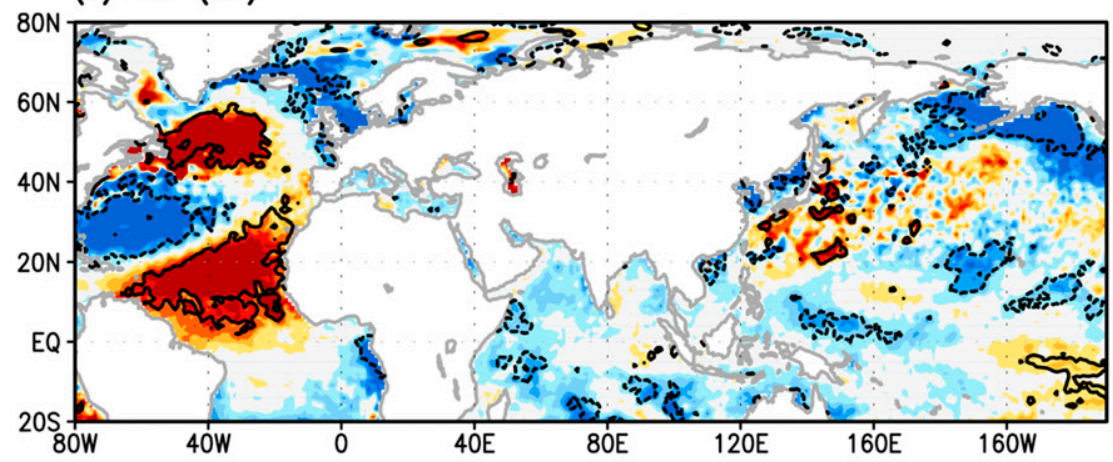

(c) SST (JJA)

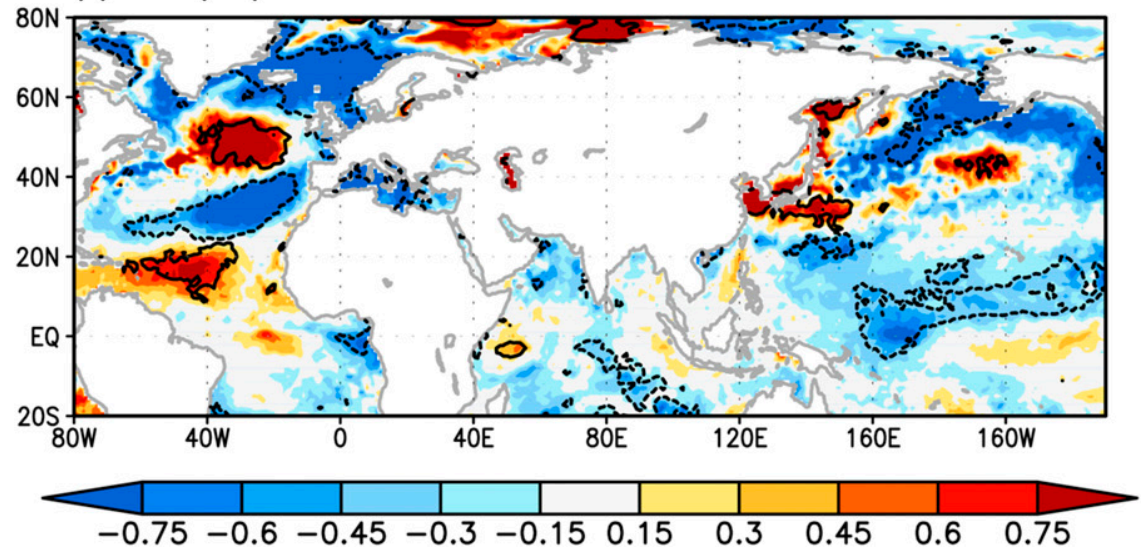

FIG. 3. Composite difference (strong - weak) maps for the (a) 2-m temperature anomaly in JJA (shading; K), (b) SST anomaly in April and May (shading; K), and (c) SST anomaly in JJA (shading; K) for the NAI (1995-2014). Contours indicate statistically significant regions at the $90 \%$ confidence level. Composite criteria are \pm 1.0 standard deviations.

with a cyclonic anomaly to the northwest of the heating and an anticyclonic anomaly to the north over the Korean Peninsula, confirming that the convection caused by the warm SSTA in the WNP can be a heat source for inducing a remote teleconnection pattern, including the enhanced geopotential height over the Korean Peninsula. An ensemble mean plot (Fig. 8b) of the 850-hPa GPH anomaly in response to forcing under each year's summertime mean background field shows a remarkable resemblance with Fig. 8a, 
(a) 300-hPa GPH (JJA)

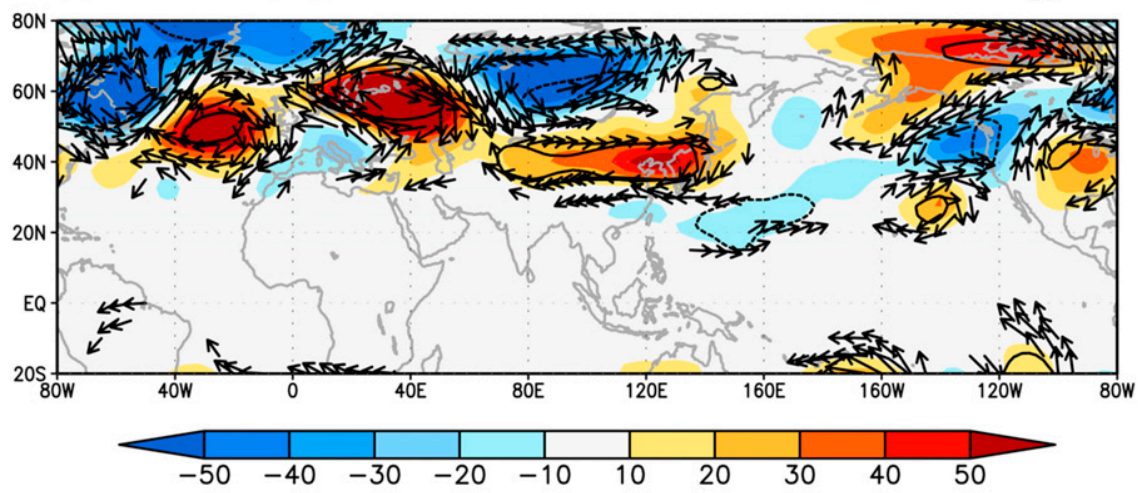

(b) $850-\mathrm{hPa}$ GPH (JJA)

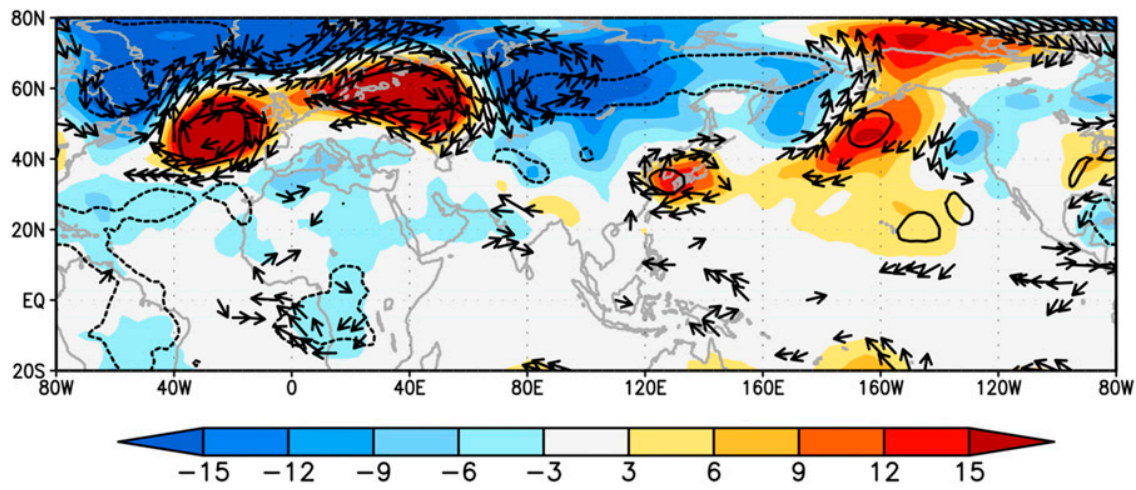

FIG. 4. Composite difference (strong - weak) maps for (a) the 300-hPa GPH anomaly (shading; gpm) and the wind anomaly (vectors; $\mathrm{m} \mathrm{s}^{-1}$ ), and (b) the 850-hPa GPH anomaly (shading; gpm) and the wind anomaly (vectors; $\mathrm{m} \mathrm{s}^{-1}$ ) in JJA for the NAI (1995-2014). Contours indicate statistically significant regions at the $90 \%$ confidence level. Composite criteria are \pm 1.0 standard deviations.

implying a robust model response to the imposed forcing.

\section{d. Dynamic process of ENPI}

The SSTAs associated with the ENPI have a tripolar meridional pattern over the Pacific during May (Fig. 9a). The positive anomalies are located over the subtropical and subpolar regions and the negative one is over the central North Pacific along $30^{\circ} \mathrm{N}$. This meridional pattern closely resembles the North Pacific gyre oscillation (NPGO), which is the second empirical orthogonal function (EOF) mode of SST or sea surface height variability over the North Pacific (Di Lorenzo et al. 2008). Its atmospheric counterpart is the North Pacific Oscillation (NPO; Walker and Bliss 1932; Rogers 1981) having a dipole structure in sea level pressure or low-level geopotential height (Fig. 9b). The NPO with the meridional mode over the Pacific is linked to ENSO, influencing the East Asian climate through a "seasonal footprint mechanism" (SFM; Vimont et al. 2001, 2003; Di Lorenzo et al. 2010; Ye et al. 2016). Using the model experiment,
Vimont et al. (2001, 2003) suggested that the SSTAs in winter can persist until the following winter through the SFM; so the midlatitude stochastic forcing of the atmosphere-ocean interaction can influence the climate in the tropics, leading to the development of El Niño.

The NPO-like meridional GPH structure appearing in May (Fig. 9b) characterized by the anticyclonic circulation anomaly over the northern Pacific $\left(50^{\circ} \mathrm{N}\right)$ and the cyclonic circulation anomaly over the midlatitude Pacific $\left(30^{\circ} \mathrm{N}\right)$ deforms in June-July (JJ) (Fig. 9d). The northern anticyclonic anomaly shrinks considerably and the cyclonic circulation anomaly shifts to the southwest. The southwesterly winds develop along the southern part of the cyclonic circulation, inducing a warm SST anomaly (Fig. 9c) by the wind-evaporation-SST (WES) feedback along the equator (Xie and Philander 1994). Note that this mechanism is similar to the abovementioned SFM. At the same time, over the Maritime Continent a negative precipitation anomaly develops $\left(\sim 10^{\circ} \mathrm{S}\right.$ and $120^{\circ} \mathrm{E}$ in Fig. 10a) due to an inverted Walker circulation. 
(a) 300-hPa GPH climatological basic state running ( $\mathrm{t}=22)$

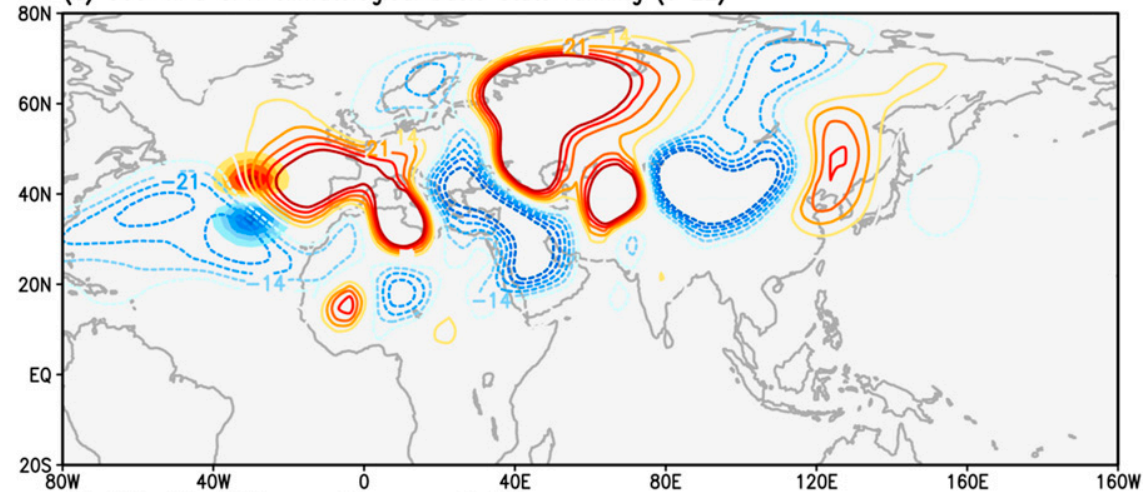

(b) $300-\mathrm{hPa}$ GPH ensemble mean $(\mathrm{t}=22)$

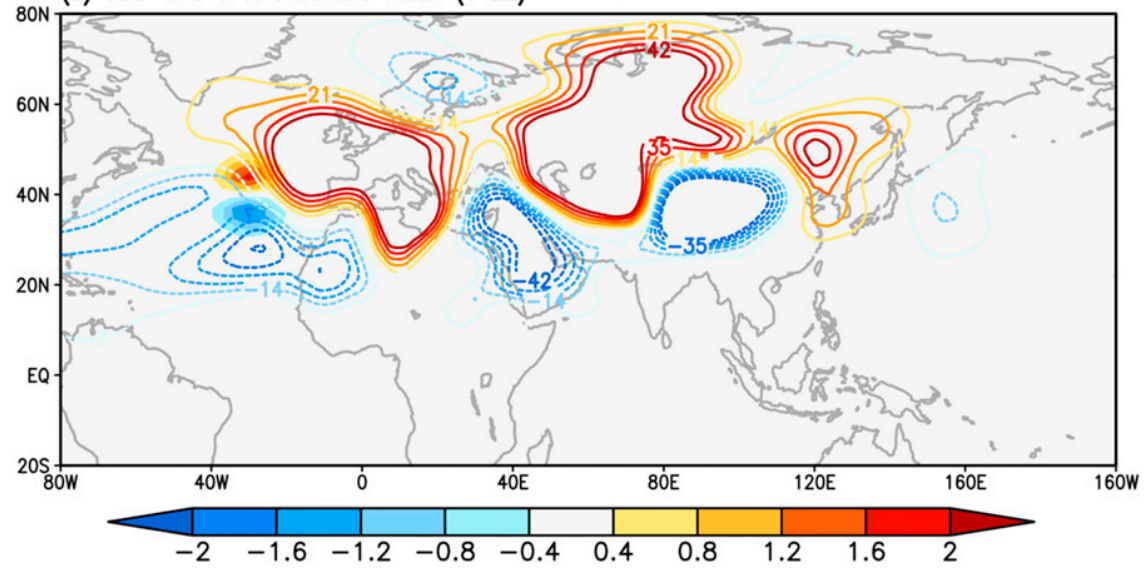

FIG. 5. The 300-hPa GPH anomaly (contour interval of $10 \mathrm{gpm}$ ) response in the GFDL model experiment. (a) Day 22 result for climatological (1995-2014) mean JJA basic state and (b) ensemble mean of day 22 results for individual JJA mean basic states during 1995-2014. Red (blue) shading indicates the vertically averaged heating rate (cooling) ( $\mathrm{K} \mathrm{day}^{-1}$ ).

In addition, the warm SST anomaly over the subtropical central Pacific and cold SST anomaly south of Japan at longitudes around $130^{\circ}-160^{\circ} \mathrm{E}$ (a box in Fig. 9c) tend to maintain and strengthen a cyclonic circulation through the air-sea interaction (Wang et al. 2000; Kim et al. 2014). That is, the cyclonic circulation anomaly over the subtropics (Fig. 9d) in response to the warm SST anomaly (Fig. 9c) there acts to weaken the trade wind (Fig. 9d) and thus evaporation, which, in turn, strengthens the warm SSTA. Meanwhile, the negative SSTA south of Japan works in a similar way with an opposite sign. So both anomalies tend to develop the positive precipitation anomaly to the east of the Philippine Sea (Fig. 10a). These two precipitation anomalies in the equatorial western Pacific and the WNP may act as external forcing centers that develop the atmospheric teleconnection pattern toward the north, including the generation of the anticyclonic circulation anomaly over the Korean Peninsula (Fig. 9d). This is tested using the dynamical core model, as shown in Fig. 11. Note that the
SST, precipitation, and 2-m temperature anomalies in JJA (not shown) are similar to those in JJ, but the $850-\mathrm{hPa}$ GPH anomaly in JJ is stronger than in JJA, so only $\mathrm{JJ}$ is presented in Fig. 10. This is mainly because the ENPI is more closely related to the extreme temperature over the Korean Peninsula in JJ than in August.

The heating and cooling anomalies are forced in the model and 15-day integration results for GPH are presented in Fig. 11. Figure 11 shows the production of an anticyclonic circulation over the Korean Peninsula and a Rossby wave train recurving toward the North Pacific in response to these diabatic forcings. The wave pattern resembles that of the WNPI experiment (Fig. 8). However, ENPI forcing shows a much stronger circulation signal compared to WNPI, which is due mainly to additional forcing by the cooling anomaly in the equatorial Maritime Continent region.

However, besides this forced experiment, we need to verify whether initial SSTAs that have formed over the ENP region can evolve into an SSTA pattern as shown in 
(a) SST (Apr)

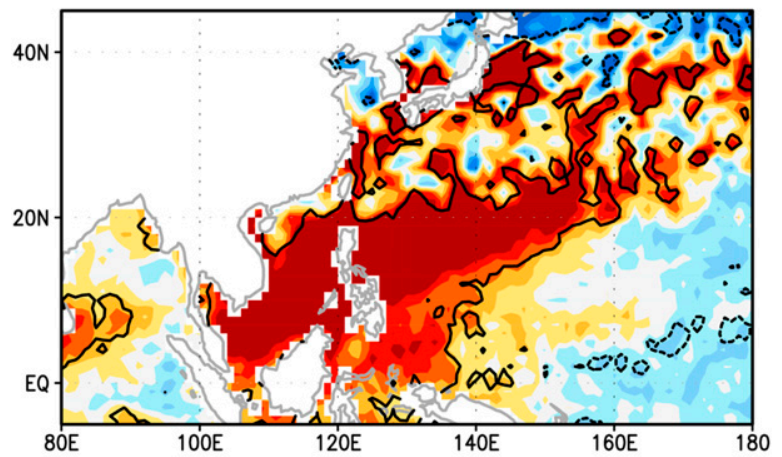

(b) SST (May)

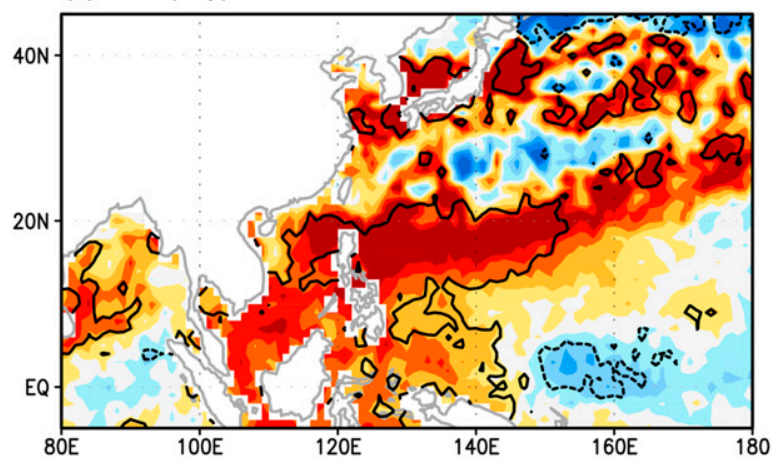

(c) SST (JJA)

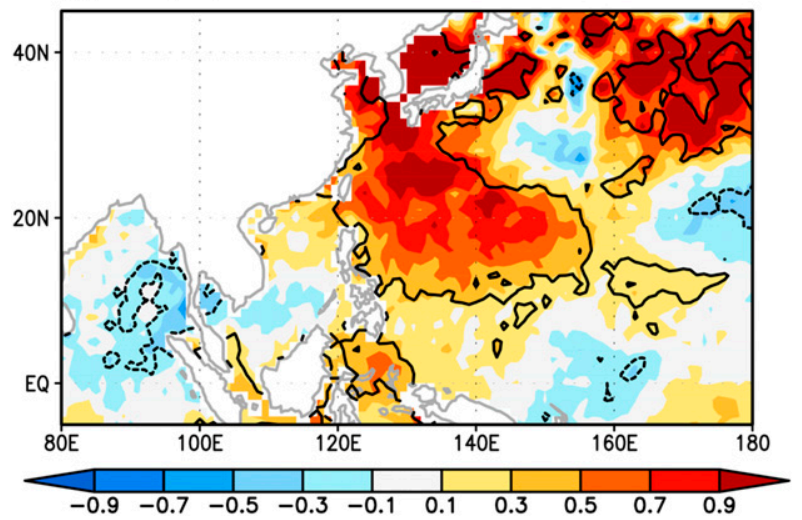

FIG. 6. Composite difference (strong - weak) maps for the SST anomaly (shading; K) for (a) April, (b) May, and (c) JJA for the WNPI (1995-2014). Contours indicate statistically significant regions at the $90 \%$ confidence level. Composite criteria are \pm 1.0 standard deviations.

Fig. $9 \mathrm{c}$ and create positive and negative precipitation areas in the western Pacific and near the Maritime Continent (Fig. 10a). For this, we employ the coupled model experiment using GFDL CM2.1. To isolate the role of the SSTA associated with the ENPI, only an SST anomaly of 1.0 standard deviation $(\sim 0.3 \mathrm{~K})$ is continuously restored in the eastern North Pacific (boxed area in Fig. 12a) during May (Park et al. 2013). Then, the results are compared to the control simulation, where its climatological SST field is (a) Precipitation (JJA)

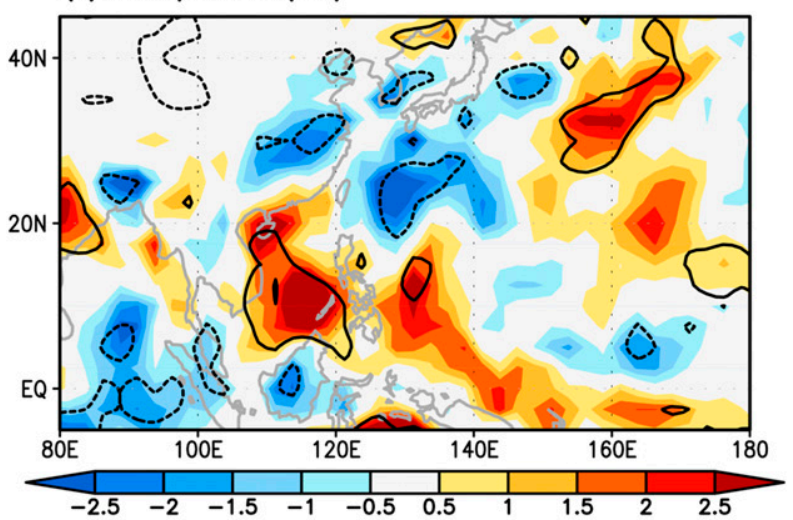

(b) 2-m temperature (JJA)

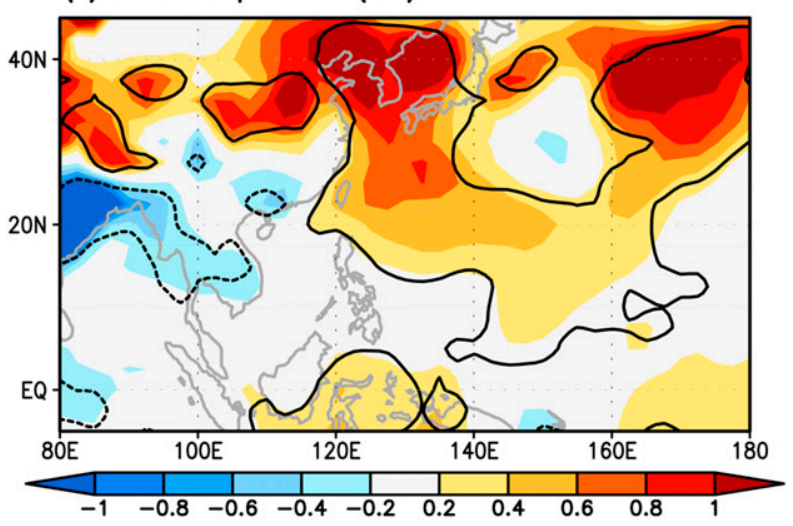

(c) $850-\mathrm{hPa}$ GPH (JJA)

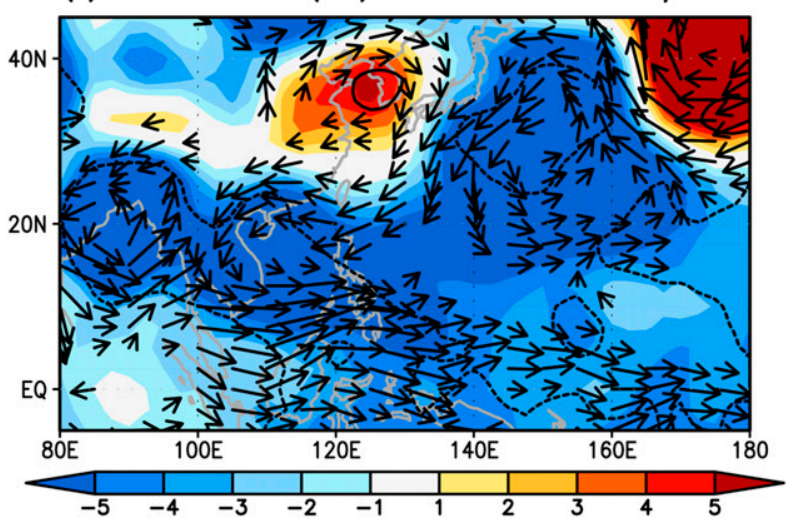

FIG. 7. Composite difference (strong - weak) maps for the (a) precipitation anomaly (shading; $\mathrm{mm} \mathrm{day}^{-1}$ ), (b) 2-m temperature anomaly (shading; K), and (c) $850-\mathrm{hPa}$ GPH anomaly (shading; gpm) and wind anomaly (vectors; $\mathrm{m} \mathrm{s}^{-1}$ ) during JJA for the WNPI (1995-2014). Contours indicate statistically significant regions at the $90 \%$ confidence level. Composite criteria are \pm 1.0 standard deviations.

restored in the box. Coupled simulations with 10 different sets of initial conditions are performed in both forcing and climatological experiments. The impact of the enhanced SST forcing over the ENPI region can be evaluated by 


\section{(a) $850-\mathrm{hPa}$ GPH climatological basic state running $(\mathrm{t}=15)$}

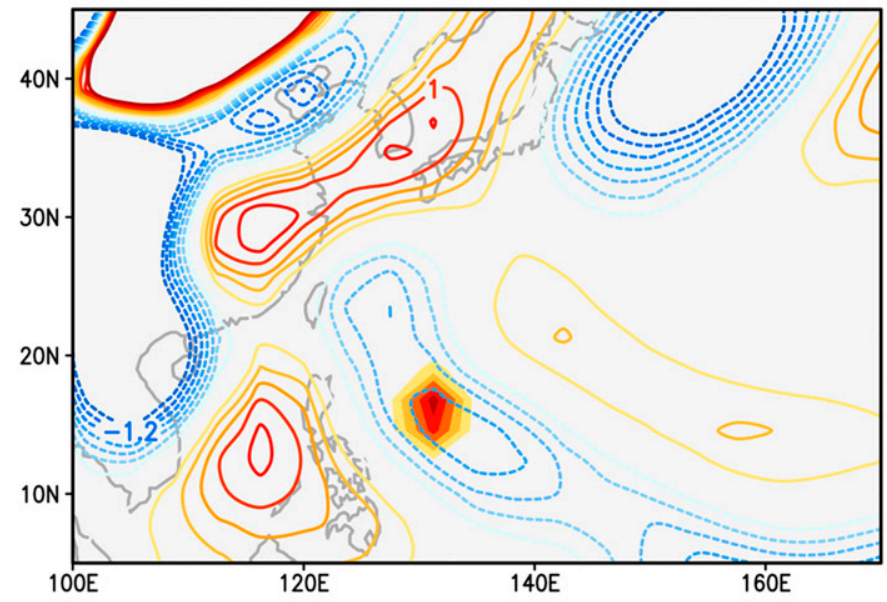

(b) $850-\mathrm{hPa}$ GPH ensemble mean $(\mathrm{t}=15)$
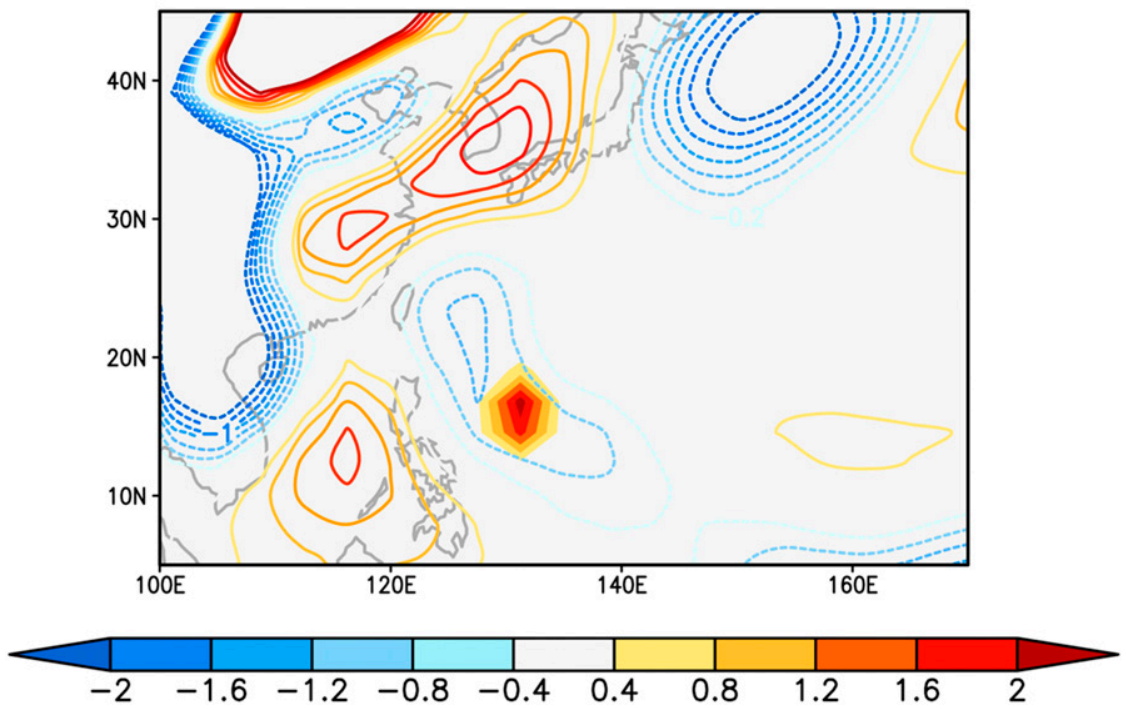

FIG. 8. The 850-hPa GPH anomaly (contour interval of $0.2 \mathrm{gpm}$ ) response to the GFDL model experiment. (a) Day 15 result for the climatological (1995-2014) mean JJA basic state and (b) the ensemble mean of the day 15 results for individual JJA mean basic states during 1995-2014. Shading indicates a vertically averaged heating rate $\left(\mathrm{K} \mathrm{day}^{-1}\right)$.

subtracting the ensemble mean of the control simulations from that of the forcing runs. The results of the experiments show the development of a central Pacific (CP) El Niñolike SST anomaly pattern and a meridionally oppositesigned SST anomaly pattern around $160^{\circ} \mathrm{E}$ (near the box in Fig. 9c) during the summertime (Fig. 12a). The equatorial SST pattern weakens the Walker circulation, inducing a negative precipitation anomaly over the equatorial western Pacific, and the cyclonic circulation over the WNP associated with a dipole-like SSTA pattern gives rise to a positive precipitation anomaly (Figs. 12b,c). Like the previous GFDL dynamical core model experiments, the anticyclonic circulation and high temperatures develop over the Korean Peninsula (Figs. 12b,d). Note that the 850-hPa height field from the coupled model (Fig. 12b) looks different than that of the observations (Fig. 9d) and the atmospheric model results (Fig. 11). One possible reason is that the pattern in Fig. $12 \mathrm{~b}$ is a result of the 10 -member ensemble mean, where atmospheric internal variability is canceled. However, the most important two anomalies-the cyclonic and anticyclonic circulation anomalies over the WNP and the Korean Peninsula, respectivelyappear commonly in the observations and models.

Therefore, the ENPI can induce the CP El Niñolike SST anomaly pattern over the central Pacific, 
(a) SST (May)

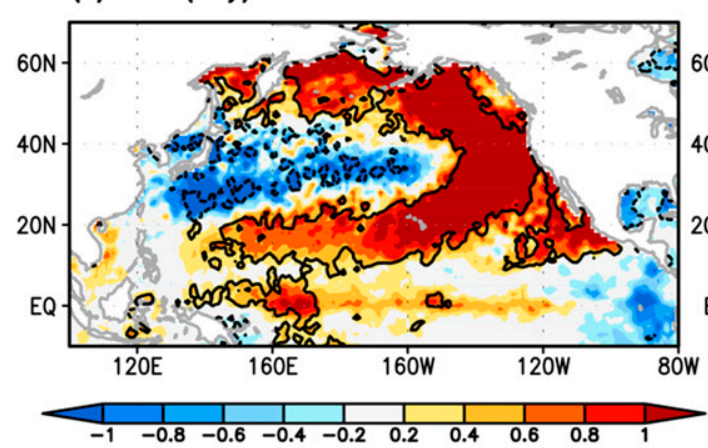

(c) SST (JJ)

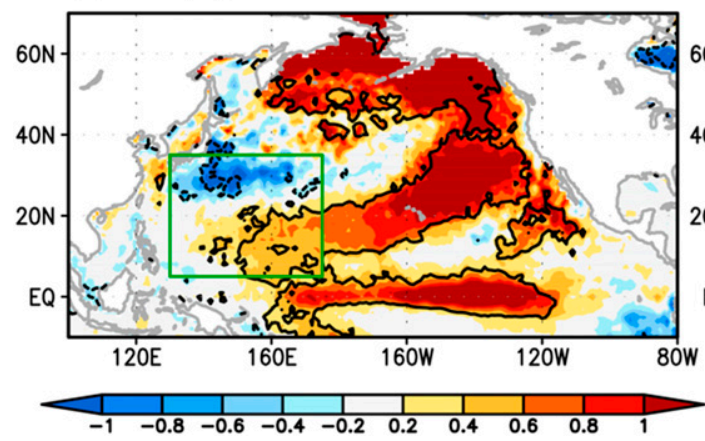

(b) 850-hPa GPH (May)

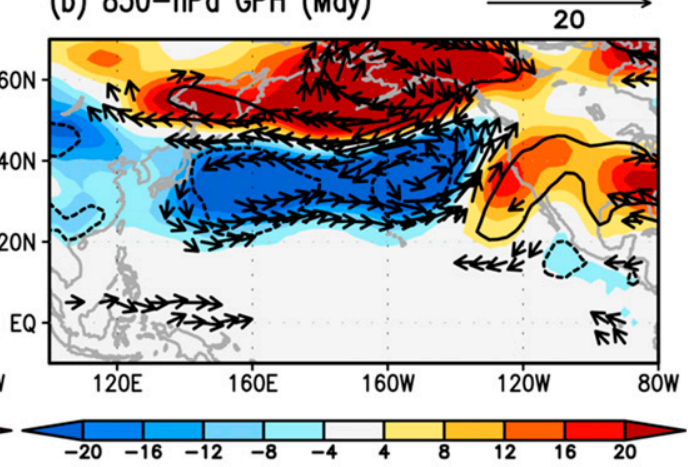

(d) $850-\mathrm{hPa}$ GPH (JJ)

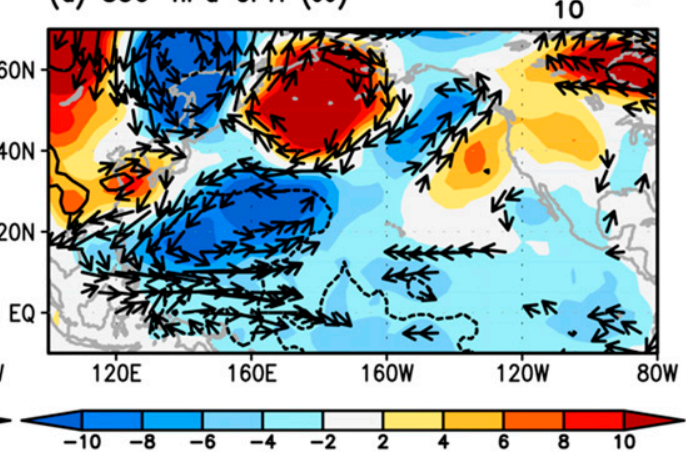

FIG. 9. Composite difference (strong - weak) maps for the SST anomaly (shading; K) in (a) May and (c) in June and July, and 850-hPa geopotential height anomaly (shading; gpm) and wind anomaly (vectors; $\mathrm{m} \mathrm{s}^{-1}$ ) in (b) May and (d) in June and July for the ENPI (1995-2014). Contours indicate statistically significant regions at the $90 \%$ confidence level. Composite criteria are \pm 1.0 standard deviations. A green box indicates negative and positive SST anomaly patterns that induce a cyclonic circulation anomaly in between.

through which the Walker circulation is inverted and negative diabatic heating develops over the Maritime Continent. In the off-equatorial western Pacific region (around $160^{\circ} \mathrm{E}$ ), air-sea interaction related to the WES feedback maintains the cyclonic circulation anomaly that produces a positive precipitation anomaly. The SFM works as a precursor signal, and the evolution of the initial NPGO mode generates the diabatic heating/ cooling anomaly that tends to drive the atmospheric teleconnection to the north and northeast.

\section{Empirical model}

The normalized SST anomaly time series of the explanatory variables (NAI, WNPI, and ENPI) are used in constructing the statistical model. The multiple linear regression model for the first set of training data (i.e., 1995-2010) is

$$
\hat{y}=0.63 \times \mathrm{NAI}+0.56 \times \mathrm{WNPI}+0.59 \times \mathrm{ENPI},
$$

where $\hat{y}$ indicates the response value of TX90p or predicted TX90p for the years 2015-17. Since the magnitude of the regression coefficients indicates the relative degree to which the explanatory variables contribute to the response variable, the contributions from NAI, WNPI, and ENPI are similar. A more direct contribution of each explanatory variable in explaining the interannual variation of the TX90p index can be estimated by a difference in the correlation coefficient calculated after removing the corresponding explanatory variable from the whole regression model (Neter et al. 1996; Wang et al. 2017). A reduction of the correlation is fairly similar among the three explanatory variables (0.30-0.35), as is consistent with the similar range of magnitudes shown in the above regression coefficients. Figure 13 shows the observed extreme temperature frequency (TX90p index) and the extreme temperature frequency calculated by our empirical model in a bar plot, with the correlation coefficient and MSSS between those two being $\sim 0.77$ and $\sim 0.56$, respectively. These cross-validated skill scores are all considered statistically significant. A $3 \times 3$ contingency table shows that 17 years (approximately $78 \%$ of the total year) are correctly predicted according to the tercile skill validation 
(a) Precipitation (JJ)

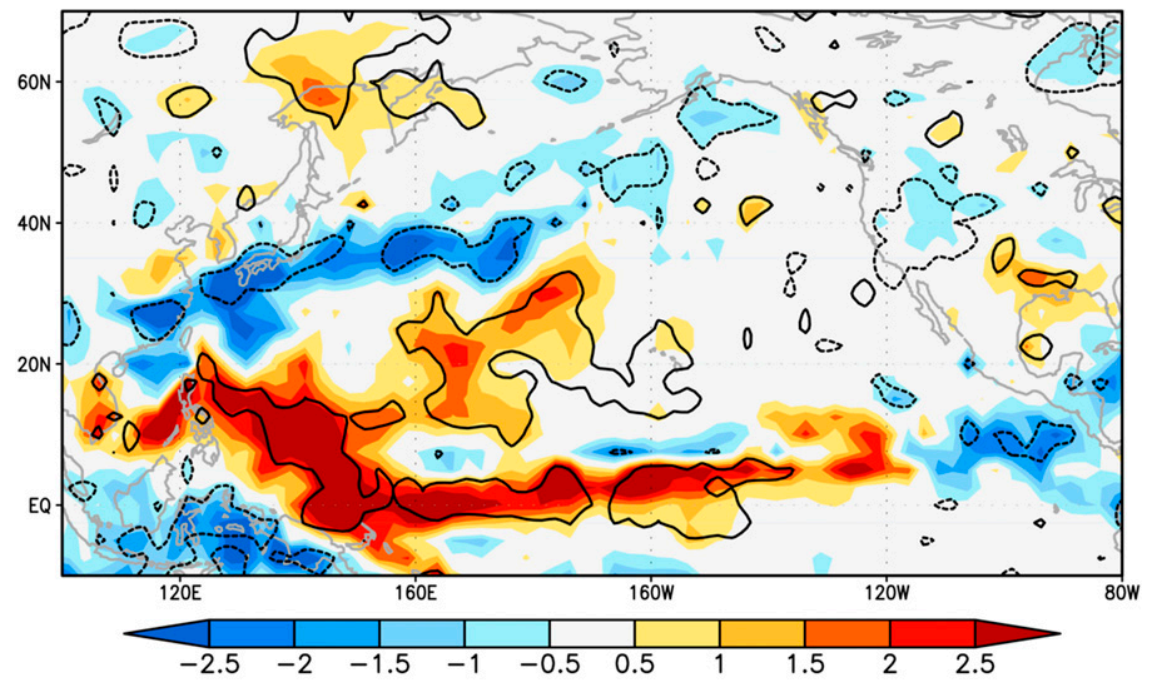

(b) 2-m temperature (JJ)

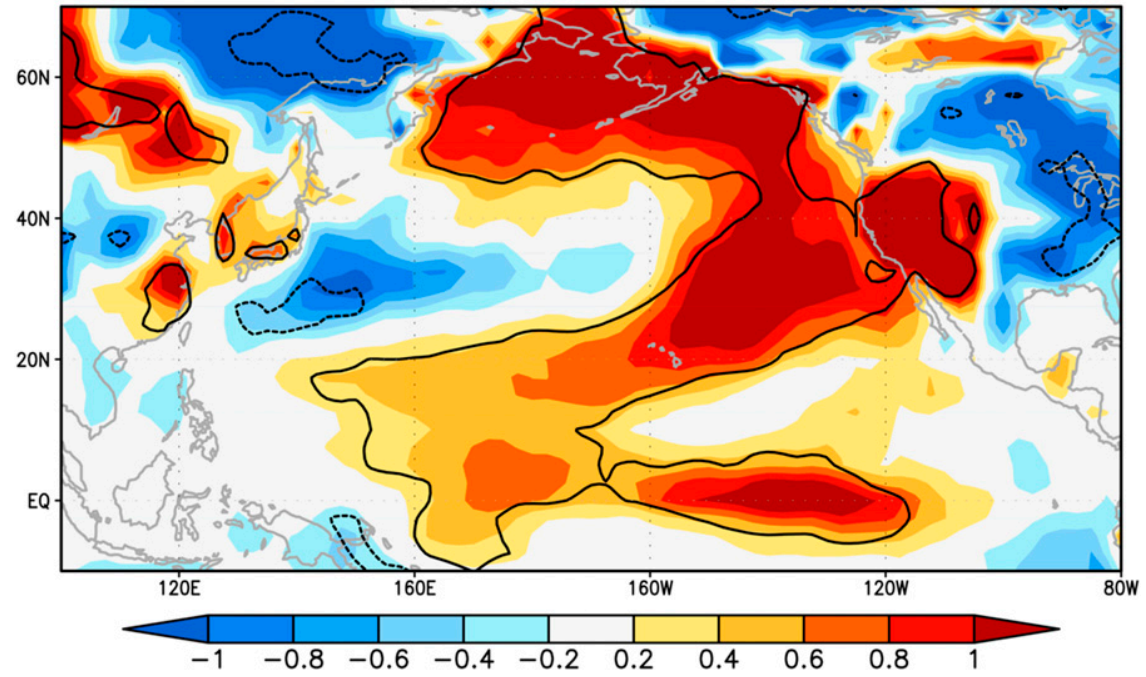

FIG. 10. Composite difference (strong - weak) maps for (a) precipitation anomaly (shading; mm day ${ }^{-1}$ ) and (b) 2-m temperature anomaly (shading; K) in June and July for the ENPI (1995-2014). Contours indicate statistically significant regions at the $90 \%$ confidence level. Composite criteria are \pm 1.0 standard deviations.

framework (see Table 3), and the GMSS is as high as $\sim 0.74$. Consequently, through the various assessments of skill measures, it is seen that our empirical model is regarded as a skillful regression scheme.

\section{Summary}

In this study, we have constructed an empirical model to diagnose the impact of explanatory variables that affect the frequency of extreme temperature events over South Korea. The TX90p time series are used to represent the interannual variation of this frequency during
JJA. A forward stepwise regression technique identifies three independent and physically meaningful explanatory variables: springtime SSTAs in the North Atlantic, the western North Pacific, and the eastern North Pacific (where the related time series are referred to as NAI, WNPI, and ENPI, respectively).

To ensure the validity of the three explanatory variables, physical processes involved in the individual explanatory variables are investigated. In association with the NAI, an NAO-related dipolar SST anomaly pattern appears in the North Atlantic. The dipole SSTAs act as the quasi-stationary forcing for Rossby waves, which 
(a) 850-hPa GPH climatological basic state running ( $t=15)$

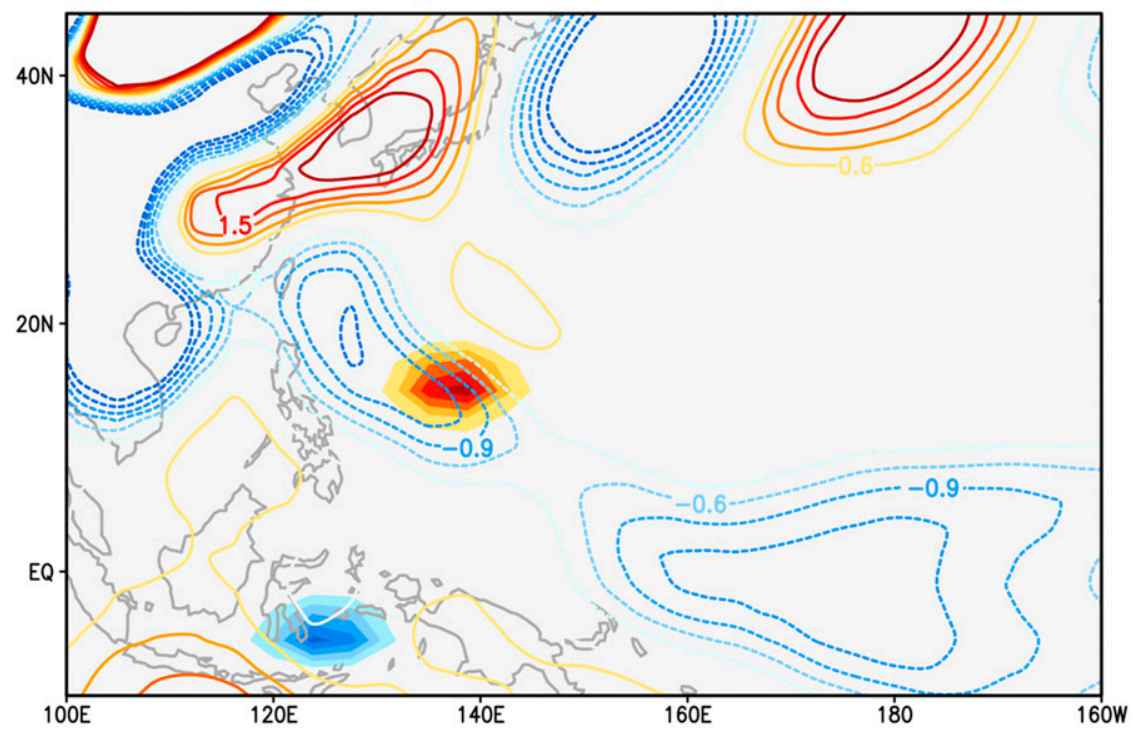

(b) $850-h P a$ GPH ensemble mean $(t=15)$

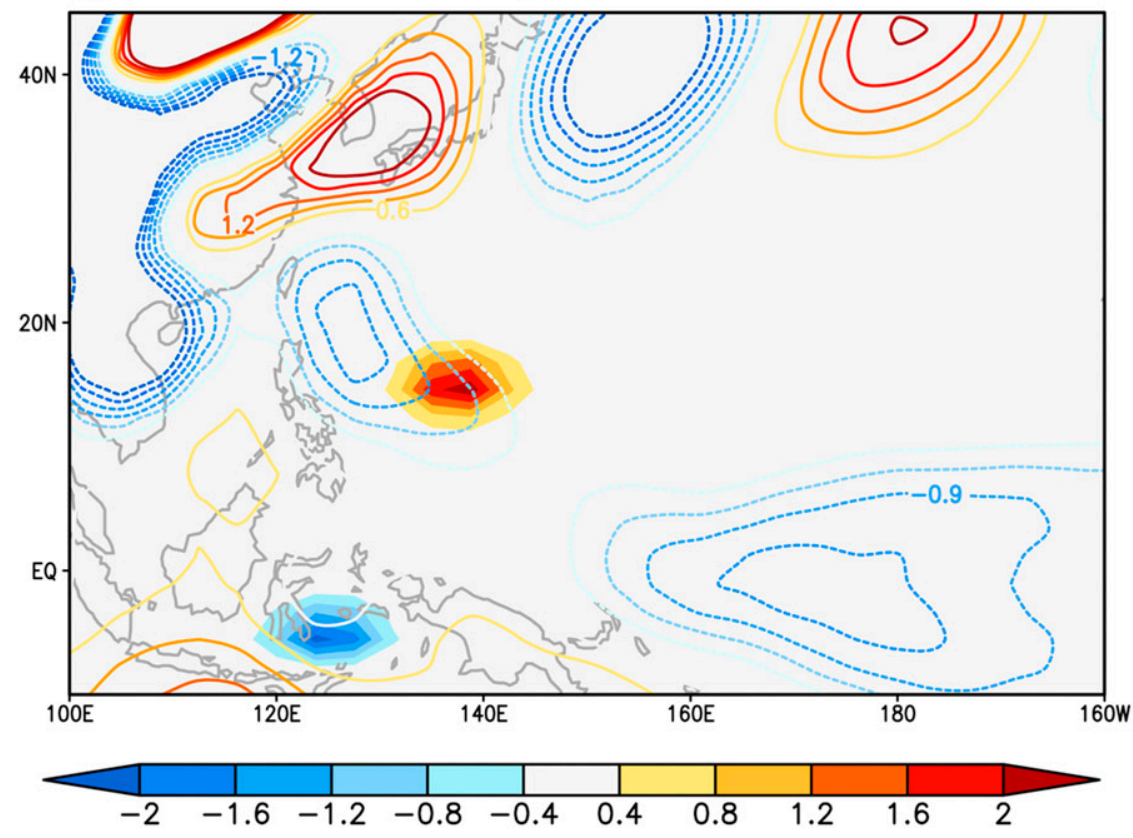

FIG. 11. The 850-hPa GPH anomaly (contour intervals of $0.3 \mathrm{gpm}$ ) response in the GFDL model experiment. (a) Day 15 result for the climatological (1995-2014) mean JJA basic state and (b) ensemble mean of day 15 results for individual JJA mean basic states during 1995-2014. Red (blue) shading indicates the vertically averaged heating (cooling) rate $\left(\mathrm{K} \mathrm{day}^{-1}\right)$.

propagate from the North Atlantic to East Asia across the northern Eurasian continent, leading to the development of an anticyclonic circulation over the Korean Peninsula. On the other hand, the WNPI predictor yields a warm SST anomaly over the Philippine Sea that persists through the summer. Through diabatic forcing over the WNP and the resulting PJ teleconnection, the anticyclonic circulation anomaly develops over the Korean Peninsula and increases the occurrence probability of extreme temperature events.

In relation to the ENPI, the North Pacific SSTA structure in May (i.e., the NPGO pattern) leads to a CP El Niño-like SSTA pattern over the equatorial central Pacific in the following season. A resulting inverted 
(a) SST (JJA)

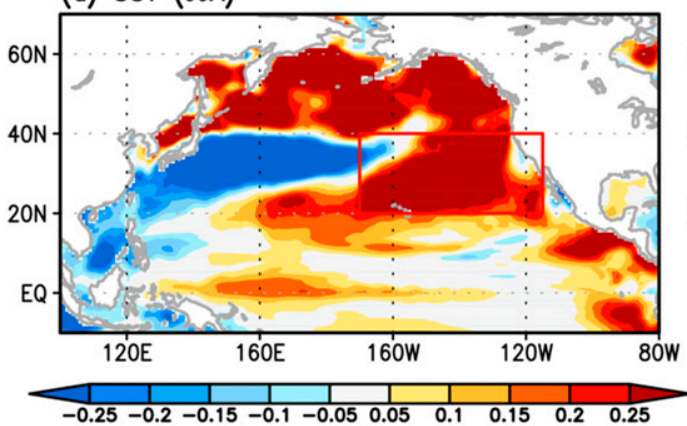

(c) Precipitataion (JJA)

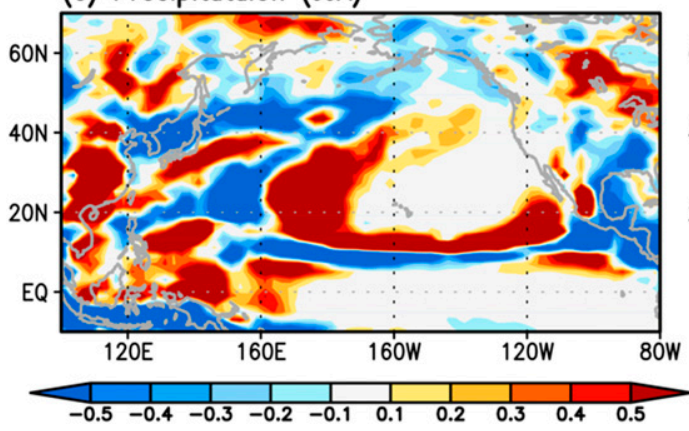

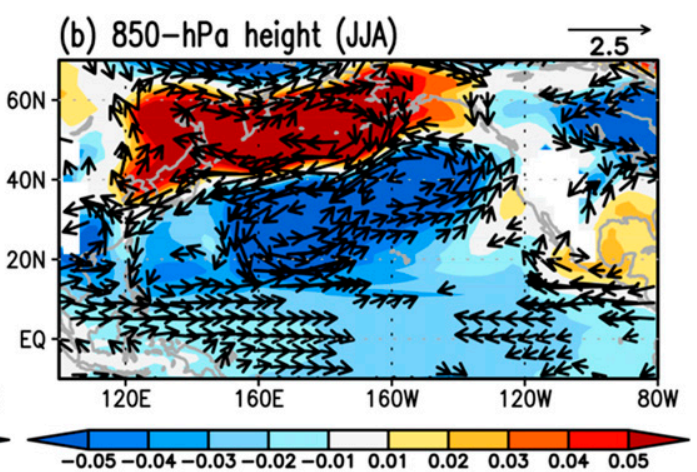

(d) Surface temperature (JJA)

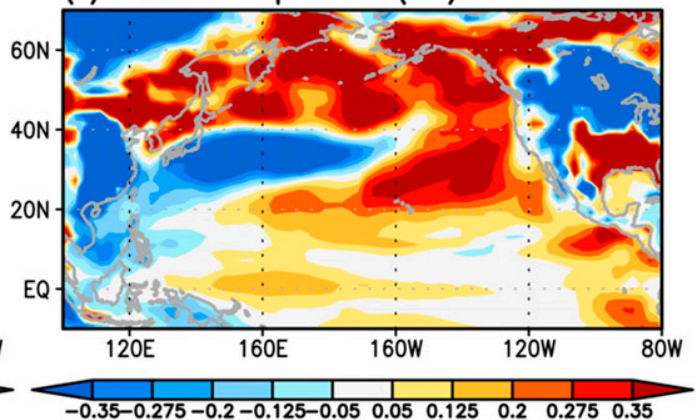

FIG. 12. Simulated (a) SST (K), (b) 850-hPa height (shading; $\mathrm{m}$ ) and winds (vectors; $\mathrm{m} \mathrm{s}^{-1}$ ), (c) precipitation rate $\left(10^{-5} \mathrm{~kg} \mathrm{~m}^{-2} \mathrm{~s}^{-1}\right)$, and (d) surface temperature $(\mathrm{K})$ for the CM2.1 model experiments. The red box is the forcing region where a 1.0 SST standard deviation is added in May for the forcing experiment.

Walker circulation produces a cooling region near the Maritime Continent. In the subtropical western Pacific, air-sea interaction characterized by the WES feedback maintains a cyclonic circulation anomaly that produces a positive precipitation anomaly. These cooling and warming anomalies over the equatorial and subtropical western Pacific excite Rossby waves, which develop the anticyclonic circulation anomaly over the
Korean Peninsula. The anticyclonic anomaly generated by the ENPI is more than $50 \%$ stronger than that by the WNPI due to the addition of the wave component forced by the cooling anomaly in the ENPI. The ENPIrelated physical processes are verified with a fully coupled atmosphere-ocean model. The 10-member ensemble result shows that the SFM and WES mechanisms operate and the tripolar SST pattern in the North

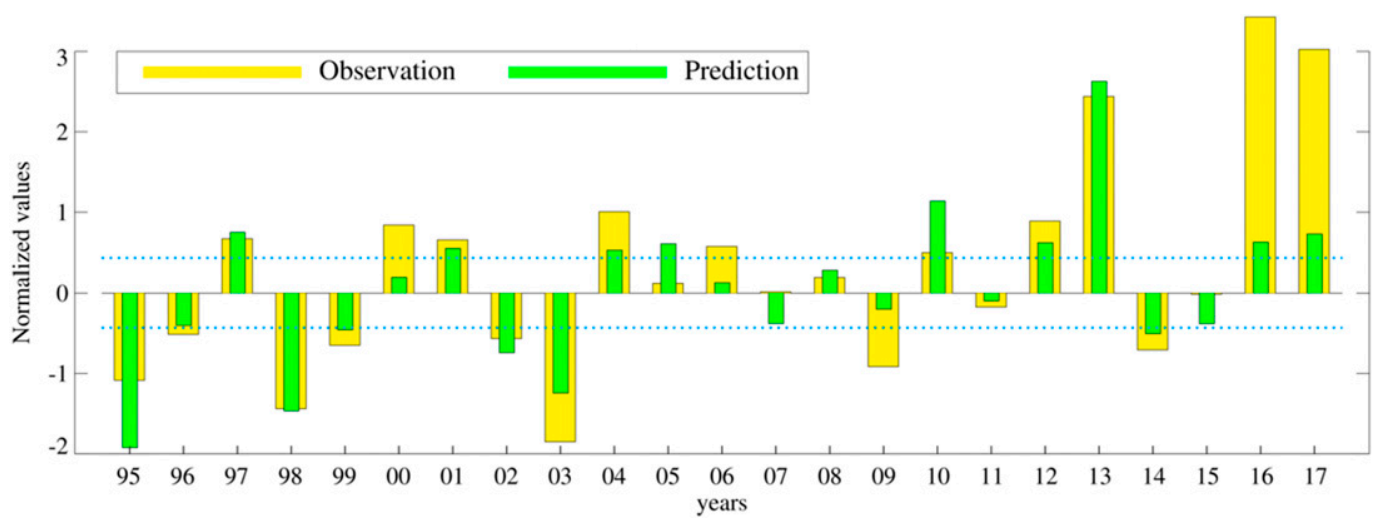

FIG. 13. Normalized values of prediction and observations for 1995-2017. The yellow bar indicates the observed TX90p, while the green bar indicates the prediction. The dotted lines are \pm 0.43 standard deviations, which represent the thresholds for tercile prediction (above normal, normal, and below normal predictions). 
TABLE 3. A $3 \times 3$ contingency table that classifies the predictions and observations by \pm 0.43 standard deviations. The percentage of the correct predictions is approximately $78.3 \%$.

\begin{tabular}{|c|c|c|c|c|}
\hline & & \multicolumn{3}{|c|}{ Prediction } \\
\hline & & Above & Normal & Below \\
\hline \multirow{3}{*}{ Observations } & Above & $\begin{array}{c}1997,2001,2004,2010,2012, \\
2013,2016,2017\end{array}$ & 2000,2006 & \\
\hline & Normal & 2005 & $2007,2008,2011,2015$ & \\
\hline & Below & & 1996, 2009 & 1995, 1998, 1999, 2002, 2003, 2014 \\
\hline
\end{tabular}

Pacific during the previous winter and spring evolves into the El Niño-like SST anomaly pattern over the central equatorial Pacific in the following summer as is consistent with the observations.

The performance of the developed multiple linear regression model is assessed through a leave-4-yr-out cross-validation method. The following model performance is achieved: correlation coefficient, 0.77; MSSS, 0.56; and GMSS, 0.74. Only five estimations are incorrect for a total of 23 years (from 1995 to 2017) from the tercile skill validation scheme. Notice that the predicted TX90p results for the years 2016 and 2017 (Fig. 13) are much smaller than is observed. In August 2016, for example, the prolonged extreme temperature events occurred due to the continued inflow of warm air from China to South Korea by atmospheric blocking episodes across the Kamchatka Peninsula. The empirical model does not contain the effect of the blocking event. Therefore, we need to investigate the physical role of blockings in the summer to improve the model's performance; this work will be conducted in the future.

Other internal variability such as the tropical intraseasonal oscillation (ISO) and the AO can impact the weather and climate of the Korean Peninsula through teleconnection (Tang et al. 2014; Min et al. 2015; Seo et al. 2016). For example, the boreal summer ISO significantly increases the frequency of extreme high temperature events over northeast Asia (Hsu et al. 2017). The modulation effect of their seasonal variance on the frequency of extreme weather events will be examined in the future.

The empirical model can be used not only as a diagnostic tool to explicitly assess the relative contribution of individual explanatory variables but also as a forecasting scheme. The developed statistical model has an advantage in that it can be applied in an easy way if the data for a few explanatory variables are available. No systematic degradation is seen in the skill performance, so the empirical model can be applied to near-future predictions. However, it should be noted that since an empirical model can have difficulties with properly predicting relevant atmospheric or oceanic variables if the climate system of concern undergoes an interdecadal change, prediction by a numerical model, which can reflect this change, has substantial merit and needs to be improved for the real application of regional climate prediction.

Acknowledgments. This work was supported by the Korea Meteorological Administration Research and Development Program under Grant KMI 2018-01012. The authors thank Dr. J.-Y. Park at Princeton University for his helpful comments on coupled simulation. We are grateful to the three anonymous reviewers for their constructive comments and suggestions, which improve the manuscript.

\section{REFERENCES}

Black, E., M. Blackburn, G. Harrison, and J. Methven, 2004: Factors contributing to the summer 2003 European heat wave. Weather, 59, 217-223, https://doi.org/10.1256/wea.74.04.

Blockeel, H., and J. Struyf, 2002: Efficient algorithms for decision tree cross-validation. J. Mach. Learn. Res., 3, 621-650.

Colombo, A., D. Etkin, and B. Karney, 1999: Climate variability and the frequency of extreme temperature events for nine sites across Canada: Implications for power usage. J. Climate, $\mathbf{1 2}$, 2490-2502, https://doi.org/10.1175/1520-0442(1999)012<2490: CVATFO $>2.0 . \mathrm{CO} ; 2$.

Coumou, D., A. Robinson, and S. Rahmstorf, 2013: Global increase in record-breaking monthly-mean temperatures. Climatic Change, 118, 771-782, https://doi.org/10.1007/s10584-012-0668-1.

Delworth, T. L., and Coauthors, 2006: GFDL's CM2 global coupled climate models. Part I: Formulation and simulation characteristics. J. Climate, 19, 643-674, https://doi.org/10.1175/JCLI3629.1.

Di Lorenzo, E., and Coauthors, 2008: North Pacific gyre oscillation links ocean climate and ecosystem change. Geophys. Res. Lett., 35, L08607, https://doi.org/10.1029/2007GL032838.

_ , K. M. Cobb, J. C. Furtado, N. Schneider, B. Anderson, A. Bracco, M. A. Alexander, and D. Vimont, 2010: Central Pacific El Niño and decadal climate change in the North Pacific. Nat. Geosci., 3, 762-765, https://doi.org/10.1038/ngeo984.

Ding, Q. H., and B. Wang, 2005: Circumglobal teleconnection in the Northern Hemisphere summer. J. Climate, 18, 3483-3505, https://doi.org/10.1175/JCLI3473.1.

Fan, K., Y. Liu, and H. Chen, 2012: Improving the prediction of the East Asian summer monsoon: New approaches. Wea. Forecasting, 27, 1017-1030, https://doi.org/10.1175/WAFD-11-00092.1.

Field, C. B., V. Barros, T. F. Stocker, and Q. Dahe, Eds., 2012: Managing the Risks of Extreme Events and Disasters to 
Advance Climate Change Adaptation. Cambridge University Press, $582 \mathrm{pp}$.

Gandin, L., and A. H. Murphy, 1992: Equitable skill scores for categorical forecasts. Mon. Wea. Rev., 120,361-370, https://doi.org/ 10.1175/1520-0493(1992)120<0361:ESSFCF >2.0.CO;2.

Gerrity, J. P., Jr., 1992: A note on Gandin and Murphy's equitable skill score. Mon. Wea. Rev., 120, 2709-2712, https://doi.org/ 10.1175/1520-0493(1992)120<2709:ANOGAM > 2.0.CO;2.

Gill, A. E., 1980: Some simple solutions for heat-induced tropical circulation. Quart. J. Roy. Meteor. Soc., 106, 447-462, https:// doi.org/10.1002/qj.49710644905.

Gordon, C. T., and W. F. Stern, 1982: A description of the GFDL Global Spectral Model. Mon. Wea. Rev., 110, 625-644, https:// doi.org/10.1175/1520-0493(1982)110<0625:ADOTGG > 2.0.CO;2.

Griffies, S. M., 2012: Elements of the Modular Ocean Model (MOM). NOAA/Geophysical Fluid Dynamics Laboratory Tech. Rep. 7, 618 pp.

Hall, N. M. J., J. Derome, and H. Lin, 2001: The extratropical signal generated by a midlatitude SST anomaly. Part I: Sensitivity at equilibrium. J. Climate, 14, 2035-2053, https://doi.org/10.1175/ 1520-0442(2001)014<2035:TESGBA > 2.0.CO;2.

Hartmann, D. L., and Coauthors, 2014: Observations: Atmosphere and surface. Climate Change 2013: The Physical Science Basis, T. F. Stocker et al., Eds., Cambridge University Press, 159-254.

Horton, D. E., N. C. Johnson, D. Singh, D. L. Swain, B. Rajaratnam and N. S. Diffenbaugh, 2015: Contribution of changes in atmospheric circulation patterns to extreme temperature trends. Nature, 522, 465-469, https://doi.org/10.1038/nature14550.

Hsu, P.-H., J.-Y. Lee, K.-J. Ha, and C.-H. Tsou, 2017: Influences of boreal summer intraseasonal oscillation on heat waves in monsoon Asia. J. Climate, 30, 7191-7211, https://doi.org/10.1175/ JCLI-D-16-0505.1.

Huffman, G. J., and Coauthors, 1997: The Global Precipitation Climatology Project (GPCP) combined precipitation dataset. Bull. Amer. Meteor. Soc., 78, 5-20, https://doi.org/10.1175/ 1520-0477(1997)078<0005:TGPCPG > 2.0.CO;2.

Imada, Y., S. Shiogma, M. Watanabe, M. Mori, M. Ishii, and M. Kimoto, 2014: The contribution of anthropogenic forcing to the Japanese heat waves of 2013 [in "Explaining Extreme Events of 2015 from a Climate Perspective"']. Bull. Amer. Meteor. Soc., 95 (9), S52-S54, https://doi.org/10.1175/ 1520-0477-95.9.S1.1.

Jeong, J.-H., and Coauthors, 2017: The status and prospect of seasonal climate prediction of climate over Korea and East Asia: A review. Asia-Pac. J. Atmos. Sci., 53, 149-173, https:// doi.org/10.1007/s13143-017-0008-5.

Kanamitsu, M., W. Ebisuzake, J. Woolen, S.-K. Yang, J. J. Hnilo, M. Fiorino, and G. L. Potter, 2002: NCEP-DOE AMIP-II Reanalysis (R-2). Bull. Amer. Meteor. Soc., 83, 1631-1643, https://doi.org/10.1175/BAMS-83-11-1631.

Kawamura, R., T. Murakami, and B. Wang, 1996: Tropical and midlatitude 45-day perturbations over the western Pacific during the northern summer. J. Meteor. Soc. Japan, 74, 867890, https://doi.org/10.2151/jmsj1965.74.6_867.

Kim, J.-W., S.-W. Yeh, and E.-C. Chang, 2014: Combined effect of El Niño-Southern Oscillation and Pacific decadal oscillation on the East Asian winter monsoon. Climate Dyn., 42, 957-971, https://doi.org/10.1007/s00382-013-1730-z.

Kim, J.-Y., K.-H. Seo, J.-H. Son, and K.-J. Ha, 2017: Development of statistical prediction models for changma precipitation: An ensemble approach. Asia-Pac. J. Atmos. Sci., 53, 207-216, https://doi.org/10.1007/s13143-017-0027-2.
Kornhuber, K., V. Petoukhov, S. Petri, S. Rahmstorf, and D. Coumou, 2017: Evidence for wave resonance as a key mechanism for generating high-amplitude quasi-stationary waves in boreal summer. Climate Dyn., 49, 1961-1979, https://doi.org/10.1007/ s00382-016-3399-6.

Kwon, M.-H., J.-G. Jhun, B. Wang, S.-I. An, and J.-S. Kug, 2005: Decadal change in relationship between East Asian and WNP summer monsoons. Geophys. Res. Lett., 32, L16709, https:// doi.org/10.1029/2005GL023026.

Kysely, J., and J. Kim, 2009: Mortality during heat waves in South Korea, 1991-2005: How exceptional was the 1994 heat wave? Climate Res., 38, 105-116, https://doi.org/10.3354/cr00775.

Lau, W. K. M., and K.-M. Kim, 2012: The 2010 Pakistan flood and Russian heat wave: Teleconnection of hydrometeorological extremes. J. Hydrometeor., 13, 392-403, https://doi.org/ 10.1175/JHM-D-11-016.1.

Lee, S.-E., and K.-H. Seo, 2013: The development of a statistical forecast model for changma. Wea. Forecasting, 28, 1304-1321, https://doi.org/10.1175/WAF-D-13-00003.1.

Lee, W.-S., and M.-I. Lee, 2016: Interannual variability of heat waves in South Korea and their connection with large-scale atmospheric circulation patterns. Int. J. Climatol., 36, 48154830, https://doi.org/10.1002/joc.4671.

Lepage, Y., 1971: A combination of Wilcoxon's and Ansari-Bradley's statistics. Biometrika, 58, 213-217, https://doi.org/10.1093/ biomet/58.1.213.

Lin, H., 2009: Global extratropical response to diabatic heating variability of the Asian summer monsoon. J. Atmos. Sci., 66, 2697-2713, https://doi.org/10.1175/2009JAS3008.1.

Lin, S.-J., 2004: A vertically Lagrangian finite-volume dynamical core for global models. Mon. Wea. Rev., 132, 2293-2307, https:// doi.org/10.1175/1520-0493(2004)132<2293:AVLFDC >2.0.CO;2.

Milly, P. C. D., and A. B. Shmakin, 2002: Global modeling of land water and energy balances. Part I: The Land Dynamics (LaD) model. J. Hydrometeor., 3, 283-299, https://doi.org/10.1175/ 1525-7541(2002)003<0283:GMOLWA > 2.0.CO;2.

Min, S.-K., and Coauthors, 2015: Changes in weather and climate extremes over Korea and possible causes: A review. Asia-Pac. J. Atmos. Sci., 51, 103-121, https://doi.org/10.1007/s13143-015-0066-5.

Murphy, A. H., 1988: Skill scores based on the mean square error and their relationships to the correlation coefficient. Mon. Wea. Rev., 116, 2417-2424, https://doi.org/10.1175/1520-0493(1988)116<2417: SSBOTM $>2.0 . \mathrm{CO} ; 2$.

Nakamura, H., and T. Fukamachi, 2004: Evolution and dynamics of summertime blocking over the Far East and the associated surface Okhotsk high. Quart. J. Roy. Meteor. Soc., 130, 12131233, https://doi.org/10.1256/qj.03.101.

Neter, J., M. H. Kutner, C. J. Nachtsheim, and W. Wasserman, 1996: Applied Linear Statistical Models. 4th ed. Irwin, 720 pp.

Nitta, T., 1987: Convective activities in the tropical western Pacific and their impact on the Northern Hemisphere summer circulation. J. Meteor. Soc. Japan, 65, 373-390, https://doi.org/ 10.2151/jmsj1965.65.3_373.

Park, H.-L., K.-H. Seo, and J.-H. Son, 2015: Development of a dynamics-based statistical prediction model for the changma onset. J. Climate, 28, 6647-6666, https://doi.org/10.1175/ JCLI-D-14-00502.1.

Park, J.-Y., S.-W. Yeh, J.-S. Kug, and J. Yoon, 2013: Favorable connection between seasonal footprinting mechanism and El Niño. Climate Dyn., 40, 1169-1181, https://doi.org/10.1007/ s00382-012-1477-y.

Perkins, S. E., D. Argüeso, and C. J. White, 2015: Relationships between climate variability, soil moisture, and Australian 
heatwaves. J. Geophys. Res., 120, 8144-8164, https://doi.org/ 10.1002/2015JD023592.

Reynolds, R. W., T. M. Smith, C. Liu, D. B. Chelton, K. S. Casey, and M. G. Schlax, 2007: Daily high-resolution-blended analyses for sea surface temperature. J. Climate, 20, 5473-5496, https://doi.org/10.1175/2007JCLI1824.1.

Rogers, J. C., 1981: The North Pacific Oscillation. J. Climatol., 1, 39-58, https://doi.org/10.1002/joc.3370010106.

Saha, S., and Coauthors, 2014: The NCEP Climate Forecast System version 2. J. Climate, 27, 2185-2208, https://doi.org/10.1175/ JCLI-D-12-00823.1.

Schubert, S. D., H. Wang, R. D. Koster, M. J. Suarez, and P. Ya. Groisman, 2014: Northern Eurasian heat waves and droughts. J. Climate, 27, 3169-3207, https://doi.org/10.1175/JCLI-D-1300360.1 .

Seo, K.-H., and S. Son, 2012: The global atmospheric circulation response to tropical diabatic heating associated with the Madden-Julian oscillation during northern winter. J. Atmos. Sci., 69, 79-96, https://doi.org/10.1175/2011JAS3686.1.

_- J.-H. Son, and J.-Y. Lee, 2011: A new look at changma. Korean Meteor. Soc., 21, 109-121.

$\longrightarrow,-$ - S.-E. Lee, T. Tomita, and H.-S. Park, 2012: Mechanisms of an extraordinary East Asian summer monsoon event in July 2011. Geophys. Res. Lett., 39, L05704, https://doi.org/10.1029/ 2011 GL050378.

_, — $-\longrightarrow$, and H.-S. Park, 2015: Northern East Asian monsoon precipitation revealed by airmass variability and its prediction. J. Climate, 28, 6221-6233, https://doi.org/10.1175/ JCLI-D-14-00526.1.

—- H.-J. Lee, and D. M. W. Frierson, 2016: Unraveling the teleconnection mechanisms that induce wintertime temperature anomalies over the Northern Hemisphere continents in response to the MJO. J. Atmos. Sci., 73, 3557-3571, https:// doi.org/10.1175/JAS-D-16-0036.1.

Takahashi, C., M. Watanabe, H. Shiogama, Y. Imada, and M. Mori, 2016: A persistent Japanese heat wave in early August 2015: Roles of natural variability and human-induced warming [in "Explaining Extreme Events of 2015 from a Climate Perspective"]. Bull. Amer. Meteor. Soc., 97 (12), S107-S112, https://doi.org/10.1175/BAMS-D-16-0157.1.

Tang, Q., X. Zhang, and J. A. Francis, 2014: Extreme summer weather in northern mid-latitudes linked to a vanishing cryosphere. Nat. Climate Change, 4, 45-50, https://doi.org/10.1038/ nclimate2065.

Ting, M., and I. M. Held, 1990: The stationary wave response to a tropical SST anomaly in an idealized GCM. J. Atmos. Sci., 47, 2546-2566, https://doi.org/10.1175/1520-0469(1990)047<2546: TSWRTA $>2.0 . \mathrm{CO} ; 2$.

Ueda, H., and T. Yasunari, 1996: Maturing process of the summer monsoon over the western North Pacific-A coupled ocean/ atmosphere system. J. Meteor. Soc. Japan, 74, 493-508, https:// doi.org/10.2151/jmsj1965.74.4_493.

__ _ _ , and R. Kawamura, 1995: Abrupt seasonal change of large-scale convection activity over the western Pacific in northern summer. J. Meteor. Soc. Japan, 73, 795-809, https:// doi.org/10.2151/jmsj1965.73.4_795.

Vimont, D. J., D. S. Battisti, and A. C. Hirst, 2001: Footprinting: A seasonal connection between the tropics and mid-latitudes.
Geophys. Res. Lett., 28, 3923-3926, https://doi.org/10.1029/ 2001GL013435.

,-- , and $\longrightarrow$ 2003: Seasonal footprinting in the Pacific: Implications for ENSO. J. Climate, 16, 2668-2675, https:// doi.org/10.1175/1520-0442(2003)016<2668:TSFMIT>2.0.CO;2.

Walker, G., and E. Bliss, 1932: World weather V. Mem. Roy. Meteor. Soc., 4, 53-84.

Wang, B., R. Wu, and X. Fu, 2000: Pacific-East Asian teleconnection: How does ENSO affect East Asian climate? J. Climate, 13, 1517-1536, https://doi.org/10.1175/1520-0442(2000)013<1517: PEATHD $>2.0 . \mathrm{CO} ; 2$.

—, Q. Ding, X. Fu, I.-S. Kang, K. Jin, J. Shukla, and F. DoblasReyes, 2005: Fundamental challenge in simulation and prediction of summer monsoon rainfall. Geophys. Res. Lett., 32 L15711, https://doi.org/10.1029/2005GL022734.

_ - and Coauthors, 2009: Advance and prospectus of seasonal prediction: Assessment of the APCC/CliPAS 14-model ensemble retrospective seasonal prediction (1980-2004). Climate Dyn., 33, 93-117, https://doi.org/10.1007/s00382-008-0460-0.

_ B. Xiang, and J.-Y. Lee, 2013: Subtropical high predictability establishes a promising way for monsoon and tropical storm predictions. Proc. Natl. Acad. Sci. USA, 110, 2718-2722, https:// doi.org/10.1073/pnas.1214626110.

Wang, L., M. Ting, and P. J. Kushner, 2017: A robust empirical seasonal prediction of winter NAO and surface climate. Sci. Rep., 7, 279, https://doi.org/10.1038/s41598-017-00353-y.

Wilks, D. S., 2006: Statistical Methods in the Atmospheric Sciences. 2nd ed. Academic Press, $630 \mathrm{pp}$.

Winton, M., 2000: A reformulated three-layer sea ice model. J. Atmos. Oceanic Technol., 17, 525-531, https://doi.org/10.1175/15200426(2000)017<0525:ARTLSI >2.0.CO;2.

WMO, 2010: Attachment II. Global Aspects, Vol. I, Manual on the Global Data-Processing and Forecasting System, World Meteorological Organization Rep. WMO-485, II.8-1-II.8-17.

Wu, Z., B. Wang, J. Li, and F.-F. Jin, 2009: An empirical seasonal prediction model of the East Asian summer monsoon using ENSO and NAO. J. Geophys. Res., 114, D18120, https://doi.org/ 10.1029/2009JD011733.

Xie, S.-P., and S. G. H. Philander, 1994: A coupled oceanatmosphere model of relevance to the ITCZ in the eastern Pacific. Tellus, 46A, 340-350, https://doi.org/10.3402/ tellusa.v46i4.15484.

, K. Hu, J. Hafner, Y. Du, G. Huang, and H. Tokinaga, 2009: Indian Ocean capacitor effect on Indo-western Pacific climate during the summer following El Niño. J. Climate, 22, 730-747, https://doi.org/10.1175/2008JCLI2544.1.

Yamaura, Y., and Y. Tomita, 2011: Spatiotemporal differences in the interannual variability of baiu frontal activity in June. Int. J. Climatol., 31, 57-71, https://doi.org/10.1002/joc.2058.

Ye, X., W. Zhang, and M. Luo, 2016: The North Pacific gyre oscillation and East Asian summer precipitation. Atmos. Sci. Lett., 17, 531-537, https://doi.org/10.1002/asl.688.

Yim, S., S. Yeh, R. Wu, and J. Jhun, 2008: The influence of ENSO on decadal variations in the relationship between the East Asian and western North Pacific summer monsoons. J. Climate, 21, 3165-3179, https://doi.org/10.1175/2007JCLI1948.1.

Yonetani, T., and G. S. McCabe, 1994: Abrupt changes in regional temperature in the conterminous United States. Climate Res. 4, 13-23, https://doi.org/10.3354/cr004013. 